\title{
Indium-Mediated Reductive Cyclizations of Optically Active Iodoalkynes: Synthesis and Biological Evaluation for HIV-Protease Inhibitors
}

Reiko Yanada, ${ }^{1 *}$ Yasuhiro Koh, ${ }^{2}$ Nobuaki Nishimori, ${ }^{1}$ Akira Matsumura, ${ }^{1}$ Shingo Obika, ${ }^{1}$ Hiroaki Mitsuya, ${ }^{2,3}$ Nobutaka Fujii, ${ }^{1}$ Yoshiji Takemoto ${ }^{1 *}$

${ }^{1}$ Graduate School of Pharmaceutical Sciences, Kyoto University, Yoshida, Sakyo-ku, Kyoto 6068501, Japan

${ }^{2}$ Department of Internal Medicine II, Kumamoto University School of Medicine, Kumamoto, Japan ${ }^{3}$ Experimental Retrovirology Section, Medicine Branch, Division of Clinical Sciences, National Cancer Institute, National Institute of Health, Bethesda, Maryland 20892, USA

\section{Table of Contents}

Page No.

General S2

Preparation of Compounds $\mathrm{S} 2-\mathrm{S} 16$

${ }^{1} \mathrm{H}$ and ${ }^{13} \mathrm{C}-\mathrm{NMR}$ Spectra of Compounds S17 - S37 
General. All reactions were carried out under a positive pressure of argon or nitrogen. ${ }^{1} \mathrm{H}$ NMR spectra were recorded on a JEOL JNM-EX-270 or JEOL JNM-LA-500 spectrometer using tetramethylsilane (TMS) as an internal standard. ${ }^{13} \mathrm{C}$ NMR spectra were recorded on a JEOL JNMEX-270 (67.8 MHz) or JEOL JNM-LA-500 (125.0 MHz) spectrometer spectrometer. Nominal (LRMS) and exact mass (HRMS) spectra were recorded on a JEOL JMS-HX/HX-110A instrument. Metallic indium was purchased from Kojundo Chemical Laboratory Co., Ltd. For flash chromatography, silica gel FL60D (Fuji Silysia Chemical Ltd.) and silica gel 60N (Kanto Chemical Co. Inco.) were employed.

\section{Preparation of 2-butynyloxy-3-iodo-tetrahydropyran (2)}

To a stirred, ice-cold suspension of $2.410 \mathrm{~g}(10.71 \mathrm{mmol})$ of $N$-iodosuccinimide in $2.5 \mathrm{ml}$ of dichloromethane was added a mixture of 3,4-dihydro-2H-pyran (600 mg, $7.14 \mathrm{mmol})$ and 2-butyn1-ol $(525 \mathrm{mg}, 7.50 \mathrm{mmol})$ in $2.5 \mathrm{ml}$ of dichloromethane over $5 \mathrm{~min}$. After warming to room temperature with stirring over $2 \mathrm{~h}, 5 \mathrm{ml}$ of water was added, and the stirring was continued for $1 \mathrm{~h}$. The layers were separated and aqueous layer was extracted with 2 x $60 \mathrm{ml}$ of ethyl acetate. The combined organic extracts were washed with $10 \%$ aqueous $\mathrm{Na}_{2} \mathrm{~S}_{2} \mathrm{O}_{3}(2 \times 10 \mathrm{ml})$ and brine solution, dried over anhydrous $\mathrm{K}_{2} \mathrm{CO}_{3}$, filtered, and concentrated. Chromatography over silica gel using $9 \%$ diethyl ether in hexane afforded the title iodo ether $2(1.786 \mathrm{~g}, 89 \%)$ as an yellow oil.

2: ${ }^{1} \mathrm{H}-\mathrm{NMR}\left(\mathrm{CDCl}_{3}, 500 \mathrm{MHz}\right) \delta 1.54-1.57(\mathrm{~m}, 1 \mathrm{H}), 1.83-1.88(\mathrm{~m}, 1 \mathrm{H}), 1.86(\mathrm{~s}, 3 \mathrm{H}), 1.98-2.03$ (m, 1H), 2.32-2.36 (m, 1H), 3.59-3.63 (m, 1H), 3.93-3.95 (m, 1H), 4.12-4.20 (m, 1H), $4.22(\mathrm{~d}, J=$ $15.2 \mathrm{~Hz}, 1 \mathrm{H}), 4.28(\mathrm{~d}, J=15.2 \mathrm{~Hz}, 1 \mathrm{H}), 4.87(\mathrm{~d}, J=4.6 \mathrm{~Hz}, 1 \mathrm{H}) ;{ }^{13} \mathrm{C}-\mathrm{NMR}\left(\mathrm{CDCl}_{3}, 67.8 \mathrm{MHz}\right) \delta$ 3.7, 24.7, 28.7, 31.7, 55.4, 62.9, 74.2, 83.1, 100.1; LRMS (EI) $m / z 280\left(\mathrm{M}^{+}\right)$; HRMS $m / z$ calcd for $\mathrm{C}_{9} \mathrm{H}_{13} \mathrm{O}_{2} \mathrm{I} 279.9962$, found 279.9960; IR $\left(\mathrm{CHCl}_{3}, \mathrm{~cm}^{-1}\right)$ 2952, 2858, 1439, 1375.

\section{Preparation of 3-(1-iodo-ethylidene)-hexahydro-furo[2,3-b]-pyran (2a $(E)$ and 2a $(Z))$}

To a solution of $2(140 \mathrm{mg}, 0.50 \mathrm{mmol})$ in dry methanol $(1.5 \mathrm{ml})$ was added indium (0) (57 mg, $0.50 \mathrm{mmol})$ and iodine $(63 \mathrm{mg}, 0.25 \mathrm{mmol})$. The mixture was stirred for $5 \mathrm{~h}$ at room temperature under argon atmosphere. The mixture was evaporated, filtered through a plug of celite, and concentrated in vacuo. The crude residue was purified by column chromatography $\left(\mathrm{SiO}_{2}\right.$, hexane : 
ethyl acetate $=9: 1)$ to give unseparable mixture $(84 \mathrm{mg})$ of $\mathbf{2 a}(E)(47 \%)$ and $\mathbf{2 a}(Z)(13 \%)$.

2a $(E$ and $Z):{ }^{1} \mathrm{H}-\mathrm{NMR}\left(\mathrm{CDCl}_{3}, 500 \mathrm{MHz}\right) \delta 1.30-1.64(\mathrm{~m}, 3 \mathrm{H}), 1.78-1.83(\mathrm{~m}, 1 \mathrm{H}), 2.42(\mathrm{~s}, 3 \mathrm{H})$, 2.64-2.67 (m, 1H), $3.64(\mathrm{~d}, 1 \mathrm{H}, J=11.0 \mathrm{~Hz}), 3.75-3.84(\mathrm{~m}, 1 \mathrm{H}), 3.99(\mathrm{~d}, 1 \mathrm{H}, J=14.3 \mathrm{~Hz}), 4.29(\mathrm{~d}$, $1 \mathrm{H}, J=14.3 \mathrm{~Hz}), 5.19(\mathrm{~d}, 1 \mathrm{H}, J=3.0 \mathrm{~Hz}) ;{ }^{13} \mathrm{C}-\mathrm{NMR}\left(\mathrm{CDCl}_{3}, 67.8 \mathrm{MHz}\right) \delta 22.3,22.5,28.9,45.9$, 61.1, 65.7, 85.1, 99.48, 146.3; LRMS (EI), $m / z 280\left(\mathrm{M}^{+}\right)$; HRMS $m / z$ calcd for $\mathrm{C}_{9} \mathrm{H}_{13} \mathrm{O}_{2} \mathrm{I}$ 279.9962, found 279.9961; IR $\left(\mathrm{CHCl}_{3}, \mathrm{~cm}^{-1}\right)$ 3011, 2947, 1214, 1149, 1083, 1017.

\section{3-Ethylidene-hexahydro-furo[2,3-b]pyran $(2 \mathrm{~b}(E)$ and $2 \mathrm{~b}(Z))$}

2b (E) ${ }^{1} \mathrm{H}-\mathrm{NMR}\left(\mathrm{CDCl}_{3}, 500 \mathrm{MHz}\right) \delta 1.51-1.61(\mathrm{~m}, 3 \mathrm{H}), 1.67(\mathrm{~d}, 3 \mathrm{H}, J=6.75 \mathrm{~Hz}), 1.85-1.87(\mathrm{~m}$, 1H), $2.65(\mathrm{~s}, 1 \mathrm{H}), 3.68(\mathrm{dd}, 1 \mathrm{H}, J=3.7,9.5 \mathrm{~Hz}), 3.85(\mathrm{t}, 1 \mathrm{H}, J=9.5 \mathrm{~Hz}), 4.22(\mathrm{~d}, 1 \mathrm{H}, J=12.5 \mathrm{~Hz})$, $4.53(\mathrm{~d}, 1 \mathrm{H}, J=12.5 \mathrm{~Hz}), 5.19(\mathrm{~d}, 1 \mathrm{H}, J=3.7 \mathrm{H}), 5.27(\mathrm{~d}, 1 \mathrm{H}, J=6.7 \mathrm{~Hz}) ;{ }^{13} \mathrm{C}-\mathrm{NMR}\left(\mathrm{CDCl}_{3}, 67.8\right.$ MHz) $\delta 14.1,22.6,23.7,37.3,61.3,68.4,100.8,115.1,140.3$; LRMS (EI) $m / z .154\left(\mathrm{M}^{+}\right)$; HRMS, $m / z$ calcd for $\mathrm{C}_{9} \mathrm{H}_{14} \mathrm{O}_{2}: 154.0994$, found 154.0993; IR $\left(\mathrm{CHCl}_{3}, \mathrm{~cm}^{-1}\right) 3025,2948,1618,1453,1377$, $1231,1165,1080,1040$.

2b $(Z):{ }^{1} \mathrm{H}-\mathrm{NMR}\left(\mathrm{CDCl}_{3}, 500 \mathrm{MHz}\right) \delta 1.26-1.30(\mathrm{~m}, 1 \mathrm{H}), 1.60-1.62(\mathrm{~m}, 4 \mathrm{H}), 1.83-1.90(\mathrm{~m}, 1 \mathrm{H})$, $2.60(\mathrm{~d}, 1 \mathrm{H}, J=3.7 \mathrm{~Hz}), 3.44(\mathrm{dt}, 1 \mathrm{H}, J=2.1,5.5 \mathrm{~Hz}), 3.84-3.86(\mathrm{~m}, 1 \mathrm{H}), 4.45(\mathrm{~d}, 1 \mathrm{H}, J=12.8$ $\mathrm{Hz}), 4.61(\mathrm{~d}, 1 \mathrm{H}, J=12.8 \mathrm{~Hz}), 5.13(\mathrm{~d}, 1 \mathrm{H}, J=3.7 \mathrm{~Hz}), 5.27-5.32(\mathrm{~m}, 1 \mathrm{H}) ;{ }^{13} \mathrm{C}-\mathrm{NMR}\left(\mathrm{CDCl}_{3}, 67.8\right.$ MHz) $\delta 14.4,20.4,22.6,41.8,64.5,69.2,101.6,114.0$, 137.7; LRMS (EI) $m / z 154\left(\mathrm{M}^{+}\right)$; HRMS $m / z$ calcd for $\mathrm{C}_{9} \mathrm{H}_{14} \mathrm{O}_{2}$ 154.0994, found 154.0996; IR $\left(\mathrm{CHCl}_{3}, \mathrm{~cm}^{-1}\right) 3023,2938,1603,1455,1377$, $1230,1172,1074,1038$.

\section{Preparation of 3-iodo-2-(3-phenylprop-2-ynyloxy)tetrahydropyran (3)}

To a stirred, ice cold suspension of $3.375 \mathrm{~g}(15.00 \mathrm{mmol})$ of $N$-iodosuccinimide in $2.5 \mathrm{ml}$ of dichloromethane was added a mixture of 3,4-dihydro-2H-pyran (840 mg, $10.00 \mathrm{mmol})$ and 1phenyl-1-propyn-3-ol $(1.386 \mathrm{~g}, 10.50 \mathrm{mmol})$ in $2.5 \mathrm{ml}$ of dichloromethane over $5 \mathrm{~min}$. After warming to room temperature with stirring over $2 \mathrm{~h}, 5 \mathrm{ml}$ of water was added, and the stirring was continued for $1 \mathrm{~h}$. The layers were separated and aqueous layer was extracted with $2 \times 60 \mathrm{ml}$ of ethyl acetate. The combined organic extracts were washed with $10 \%$ aqueous $\mathrm{Na}_{2} \mathrm{~S}_{2} \mathrm{O}_{3}(2 \times 10 \mathrm{ml})$ and brine solution, dried over anhydrous $\mathrm{K}_{2} \mathrm{CO}_{3}$, filtered, and concentrated. Chromatography over silica gel using $9 \%$ diethyl ether in hexane afforded the title iodo ether $3(2.820 \mathrm{~g}, 83 \%)$ as a 
colorless oil.

3: ${ }^{1} \mathrm{H}-\mathrm{NMR}\left(\mathrm{CDCl}_{3}, 500 \mathrm{MHz}\right) \delta 1.57-1.60(\mathrm{~m}, 1 \mathrm{H}), 1.85-1.86(\mathrm{~m}, 1 \mathrm{H}), 2.02-2.07(\mathrm{~m}, 1 \mathrm{H})$, 2.36-2.39 (m, 1H), 3.63-3.66 (m, 1H), 4.00-4.01 (m, 1H), 4.18 (d, 1H, J = 4.6 Hz), 4.50 (d, 1H, $J$ $=15.7 \mathrm{~Hz}), 4.55(\mathrm{~d}, 1 \mathrm{H}, J=15.7 \mathrm{~Hz}), 4.96(\mathrm{~d}, 1 \mathrm{H}, J=4.6 \mathrm{~Hz}), 7.31-7.35(\mathrm{~m}, 3 \mathrm{H}), 7.45-7.48(\mathrm{~m}$, $2 \mathrm{H}) ;{ }^{13} \mathrm{C}-\mathrm{NMR}\left(\mathrm{CDCl}_{3}, 67.8 \mathrm{MHz}\right) \delta 24.9,28.5,31.9,55.5,63.2,84.2,86.6,100.4,122.5,128.3$, 128.5, 131.8; Anal. calcd. for $\mathrm{C}_{14} \mathrm{H}_{15} \mathrm{O}_{2} \mathrm{I}, \mathrm{H}$ 4.58; C 47.27; I 38.45, found $\mathrm{H}$ 4.34; C 47.35; I 38.61; IR $\left(\mathrm{CHCl}_{3}, \mathrm{~cm}^{-1}\right) 2233,1125,1070,1026,776,738$.

\section{Preparation of 3-benzylidene-hexahydrofuro[2,3-b]-pyran $(3 \mathrm{~b}(E)$ and $3 \mathrm{~b}(Z))$}

To a solution of $\mathbf{3 b}(855 \mathrm{mg}, 2.50 \mathrm{mmol})$ in dry methanol (10 ml) was added indium (0) (290 mg, $2.52 \mathrm{mmol}$ ) and iodine $(318 \mathrm{mg}, 1.25 \mathrm{mmol})$. The mixture was stirred for $3 \mathrm{~h}$ at room temperature under argon atmosphere. The mixture was evaporated, filtered through a plug of celite, and concentrated in vacuo. The crude residue was purified by column chromatography $\left(\mathrm{SiO}_{2}\right.$, hexane : ethyl acetate $=9: 1)$ to give $\mathbf{3 b}(E)(351 \mathrm{mg}, 65 \%)$ and $\mathbf{3 b}(Z)(97 \mathrm{mg}, 18 \%)$.

3b $(E):{ }^{1} \mathrm{H}-\mathrm{NMR}\left(\mathrm{CDCl}_{3}, 500 \mathrm{MHz}\right) \delta 1.30(\mathrm{~d}, 1 \mathrm{H}, J=13.5 \mathrm{~Hz}), 1.63(\mathrm{~d}, 1 \mathrm{H}, J=11.5 \mathrm{~Hz})$, 1.93-1.97 (m, 1H), $2.10(\mathrm{~d}, 1 \mathrm{H}, J=13.5 \mathrm{~Hz}), 2.77(\mathrm{~d}, 1 \mathrm{H}, J=3.7 \mathrm{~Hz}), 3.43(\mathrm{t}, 1 \mathrm{H}, J=11.0 \mathrm{~Hz})$, $3.81(\mathrm{~d}, 1 \mathrm{H}, J=11.0 \mathrm{~Hz}), 4.78(\mathrm{dd}, 2 \mathrm{H}, J=14.1,50.8 \mathrm{~Hz}), 5.13(\mathrm{~d}, 1 \mathrm{H}, J=3.7 \mathrm{~Hz}), 6.22(\mathrm{~s}, 1 \mathrm{H})$, 7.08-7.29 (m, 5H); ${ }^{13} \mathrm{C}-\mathrm{NMR}\left(\mathrm{CDCl}_{3}, 67.8 \mathrm{MHz}\right) \delta 20.4,22.9,43.4,60.2,64.3,100.4,120.4$, 126.5, 127.8, 128.4, 136.9, 139.8; LRMS (EI) $m / z 216\left(\mathrm{M}^{+}\right)$; HRMS, $m / z$ calcd for $\mathrm{C}_{14} \mathrm{H}_{16} \mathrm{O}_{2}$ 216.1150, found 216.1156; IR $\left(\mathrm{CHCl}_{3}, \mathrm{~cm}^{-1}\right)$ 3029, 1718, 1176, 1111, 766, 747.

3b $(Z):{ }^{1} \mathrm{H}-\mathrm{NMR}\left(\mathrm{CDCl}_{3}, 500 \mathrm{MHz}\right) \delta 1.57-1.64(\mathrm{~m}, 3 \mathrm{H}), 1.98-2.04(\mathrm{~m}, 1 \mathrm{H}), 2.97(\mathrm{~s}, 1 \mathrm{H}), 3.68(\mathrm{~d}$, $1 \mathrm{H}, J=9.5 \mathrm{~Hz}), 3.89(\mathrm{~d}, 1 \mathrm{H}, J=9.5 \mathrm{~Hz}), 4.44(\mathrm{~d}, 1 \mathrm{H}, J=13.0 \mathrm{~Hz}), 4.74(\mathrm{~d}, 1 \mathrm{H}, J=13.0 \mathrm{~Hz}), 5.25$ $(\mathrm{s}, 1 \mathrm{H}), 6.30(\mathrm{~s}, 1 \mathrm{H}), 7.23-7.33(\mathrm{~m}, 5 \mathrm{H}) ;{ }^{13} \mathrm{C}-\mathrm{NMR}\left(\mathrm{CDCl}_{3}, 67.8 \mathrm{MHz}\right) \delta 22.5,23.2,38.2,61.4$, 69.8, 101.2, 121.5, 126.9, 127.8, 128.4, 136.7, 141.8; LRMS (EI) m/z $216\left(\mathrm{M}^{+}\right)$; Anal. Calc. for $\mathrm{C}_{14} \mathrm{H}_{16} \mathrm{O}_{2}$ : H 7.46; C 77.74, found: H 7.48; C 77.41; IR $\left(\mathrm{CHCl}_{3}, \mathrm{~cm}^{-1}\right) 3009,1602,1244,1176,769$, 747.

\section{Preparation of 4-iodomethylene-2-(4-methoxy-phenyl)-tetrahydrofuran (4a $(E)$ and $(Z))$}

Indium (0) (171 mg, $1.49 \mathrm{mmol})$ and iodine (189 mg, $0.74 \mathrm{mmol})$ were added to the solution of 1(2-iodo-1-prop-2-ynyloxy-ethyl)-4-methoxy-benzene 4 (470 mg, $1.49 \mathrm{mmol})$ in dry methanol (3 
$\mathrm{ml}$ ). The mixture was stirred for $18 \mathrm{~h}$ at room temperature under argon atmosphere. The mixture was extracted with 2 x $60 \mathrm{ml}$ diethyl ether. The combined organic extracts were washed with brine solution, dried over anhydrous $\mathrm{MgSO}_{4}$, filtered, and concentrated in vacuo. Chromatography over silica gel using $10 \%$ diethyl ether in hexane afforded the title product $\mathbf{4 a}(E)(137 \mathrm{mg}, 29 \%)$ and $\mathbf{4 a}$ (Z) (179 mg, 38\%) respectively as a colorless oil.

4a $(E):{ }^{1} \mathrm{H}-\mathrm{NMR}\left(\mathrm{CDCl}_{3}, 500 \mathrm{MHz}\right) \delta 2.50(\mathrm{dd}, 1 \mathrm{H}, J=9.2,16.8 \mathrm{~Hz}), 2.94(\mathrm{dd}, 1 \mathrm{H}, J=4.9,16.8$ Hz), $3.80(\mathrm{~s}, 3 \mathrm{H}), 4.35(\mathrm{~d}, 1 \mathrm{H}, J=12.8 \mathrm{~Hz}), 4.55(\mathrm{~d}, 1 \mathrm{H}, J=12.8 \mathrm{~Hz}), 4.98$ (t, 1H, J= 9.2 Hz), 6.04 $(\mathrm{s}, 1 \mathrm{H}), 6.88(\mathrm{dd}, 2 \mathrm{H}, J=2.2,6.7 \mathrm{~Hz}), 7.29(\mathrm{dd}, 2 \mathrm{H}, J=2.2,6.7 \mathrm{~Hz}) ;{ }^{13} \mathrm{C}-\mathrm{NMR}\left(\mathrm{CDCl}_{3}, 67.8\right.$ $\mathrm{MHz}) \delta 45.5,55.3,67.3,71.4,80.1,113.9,127.3,132.8,152.4,159.3 ; \mathrm{LRMS}_{\left(\mathrm{FAB}^{+}\right) \mathrm{m} / z} 317$ $\left(\mathrm{MH}^{+}\right)$; HRMS calcd for $\mathrm{C}_{12} \mathrm{H}_{14} \mathrm{O}_{2} \mathrm{I}$ 317.0040, found: 317.0027; IR $\left(\mathrm{CHCl}_{3}, \mathrm{~cm}^{-1}\right)$ 3009, 2959, 2936, 2911, 2839, 1640, 1250, 1177, 1035.

4a $(Z):{ }^{1} \mathrm{H}-\mathrm{NMR}\left(\mathrm{CDCl}_{3}, 500 \mathrm{MHz}\right) \delta 2.56(\mathrm{dt}, 1 \mathrm{H}, J=8.5,9.8 \mathrm{~Hz}), 2.94(\mathrm{dd}, 1 \mathrm{H}, J=4.9,9.8 \mathrm{~Hz})$, $3.79(\mathrm{~s}, 3 \mathrm{H}), 4.27(\mathrm{~d}, 1 \mathrm{H}, J=14.5 \mathrm{~Hz}), 4.50(\mathrm{~d}, 1 \mathrm{H}, J=14.5 \mathrm{~Hz}), 5.00$ (t, 1H, $J=9.8 \mathrm{~Hz}), 6.01(\mathrm{~s}$, $1 \mathrm{H}), 6.88(\mathrm{dd}, 2 \mathrm{H}, J=1.8,6.7 \mathrm{~Hz}), 7.29(\mathrm{dd}, 2 \mathrm{H}, J=1.8,6.7 \mathrm{~Hz}) ;{ }^{13} \mathrm{C}-\mathrm{NMR}\left(\mathrm{CDCl}_{3}, 67.8 \mathrm{MHz}\right) \delta$ 43.1, 55.2, 66.8, 75.5, 82.1, 113.7, 113.8, 127.2, 132.8, 151.4, 159.3; LRMS $\left(\mathrm{FAB}^{+}\right) \mathrm{m} / z 317\left(\mathrm{MH}^{+}\right)$; HRMS calcd for $\mathrm{C}_{12} \mathrm{H}_{14} \mathrm{O}_{2} \mathrm{I}$ 317.0040, found: 317.0027; IR $\left(\mathrm{CHCl}_{3}, \mathrm{~cm}^{-1}\right)$ 3009, 2960, 2936, 2910, 2839, 1642, 1250, 1176, 1036.

\section{Preparation of $N$-[2-iodo-1-(4-methoxy-phenyl)-ethyl]-4-methyl- $N$-prop-2-ynyl- benzenesulfonamide (5)}

To a stirred, ice cold suspension of $586 \mathrm{mg}(2.62 \mathrm{mmol})$ of $N$-iodosuccinimide in $2.5 \mathrm{ml}$ of dichloromethane was added a mixture of 4-vinylanisole $(320 \mathrm{mg}, 2.39 \mathrm{mmol})$ and $\mathrm{N}$ - $p$ toluenesulfonyl propargylamine $(500.0 \mathrm{mg}, 2.39 \mathrm{mmol})$ in $2.2 \mathrm{ml}$ of dichloromethane over $5 \mathrm{~min}$. After warming to room temperature with stirring over $2 \mathrm{~h}, 4.7 \mathrm{ml}$ of water was added, and the stirring was continued for $1 \mathrm{~h}$. The layers were separated and aqueous layer was extracted with $2 \mathrm{x}$ $60 \mathrm{ml}$ of ethyl acetate. The combined organic extracts were washed with $10 \%$ aqueous $\mathrm{Na}_{2} \mathrm{~S}_{2} \mathrm{O}_{3}(2$ $\mathrm{x} 10 \mathrm{ml}$ ) and brine solution, dried over anhydrous $\mathrm{K}_{2} \mathrm{CO}_{3}$, filtered, and concentrated. Chromatography over silica gel using 13\% diethyl ether in hexane afforded the title iodo ether 5 (785 $\mathrm{mg}, 70 \%)$ as a white solid.

5: ${ }^{1} \mathrm{H}-\mathrm{NMR}\left(\mathrm{CDCl}_{3}, 500 \mathrm{MHz}\right) \delta 2.19(\mathrm{~s}, 1 \mathrm{H}), 2.45$ (s, 3H), $3.45(\mathrm{dd}, 1 \mathrm{H}, J=2.4,18.9 \mathrm{~Hz}), 3.55$ 
(dd, 1H, $J=4.3,10.0 \mathrm{~Hz}), 3.80(\mathrm{~s}, 3 \mathrm{H}), 3.86(\mathrm{t}, 1 \mathrm{H}, J=11.3 \mathrm{~Hz}), 4.20(\mathrm{dd}, 1 \mathrm{H}, J=2.4,18.6 \mathrm{~Hz})$, $5.25(\mathrm{dd}, 1 \mathrm{H}, J=3.9,11.6 \mathrm{~Hz}), 6.85(\mathrm{~d}, 2 \mathrm{H}, J=8.5 \mathrm{~Hz}), 7.14(\mathrm{~d}, 2 \mathrm{H}, J=8.5 \mathrm{~Hz}), 7.33(\mathrm{~d}, 2 \mathrm{H}, J=$ $8.2 \mathrm{~Hz}), 7.78(\mathrm{~d}, 2 \mathrm{H}, J=8.2 \mathrm{~Hz}) ;{ }^{13} \mathrm{C}-\mathrm{NMR}\left(\mathrm{CDCl}_{3}, 67.8 \mathrm{MHz}\right) \delta 14.1,21.5,32.7,55.1,62.1,73.1$, 79.9, 113.9, 126.2, 127.3, 129.5, 129.6, 129.8, 137.3, 143.7, 159.6; Anal. calcd. for $\mathrm{C}_{19} \mathrm{H}_{20} \mathrm{NO}_{3} \mathrm{SI}$; $\mathrm{H}$ 4.26; C 48.61; I 27.08; N 2.99; O 10.23; found H 4.24; C 48.65; I 26.85; N 2.80; O 10.01; IR $\left(\mathrm{CHCl}_{3}, \mathrm{~cm}^{-1}\right): 3305,3030,3006,2962,2933,2839,1461,1335,1305,1159,1123$.

\section{Preparation of 4-iodomethylene-2-(4-methoxy-phenyl)-1-(toluene-4-sulfonyl)-pyrrolidine (5a (E) and $5 \mathbf{a}(Z))$}

To a solution of $N$-[2-Iodo-1-(4-methoxy-phenyl)-ethyl]-4-methyl- $N$-prop-2-ynylbenzenesulfonamide $5(235 \mathrm{mg}, 0.50 \mathrm{mmol})$ in dry methanol $(1.0 \mathrm{ml})$ was added indium(0) $(58 \mathrm{mg}$, $0.50 \mathrm{mmol}$ ) and iodine $(64 \mathrm{mg}, 0.25 \mathrm{mmol})$. The mixture was stirred for $18 \mathrm{~h}$ at room temperature under argon atmosphere. The mixture was extracted with 2 x $60 \mathrm{ml}$ diethyl ether. The combined organic extracts were washed with brine solution, dried over anhydrous $\mathrm{MgSO}_{4}$, filtered, and concentrated in vacuo. Chromatography over silica gel using $20 \%$ ethyl acetate in hexane afforded the title product 5a $(E)(131 \mathrm{mg}, 28 \%)$ and $\mathbf{5 a}(Z)(197 \mathrm{mg}, 42 \%)$ as a colorless and unseparable oil and $\mathbf{5 b}(14 \mathrm{mg}, 8 \%)$ as an yellow solid.

5a $(E):{ }^{1} \mathrm{H}-\mathrm{NMR}\left(\mathrm{CDCl}_{3}, 500 \mathrm{MHz}\right) \delta 2.40(\mathrm{~s}, 3 \mathrm{H}), 2.52-2.59(\mathrm{~m}, 2 \mathrm{H}), 3.79(\mathrm{~s}, 3 \mathrm{H}), 4.10(\mathrm{~s}, 1 \mathrm{H})$, 4.86-4.88 (m, 2H), $6.12(\mathrm{~s}, 1 \mathrm{H}), 6.80(\mathrm{~d}, 2 \mathrm{H}, J=8.9 \mathrm{~Hz}), 7.11(\mathrm{~d}, 2 \mathrm{H}, J=8.9 \mathrm{~Hz}), 7.23(\mathrm{~d}, 2 \mathrm{H}, J=$ $8.2 \mathrm{~Hz}), 7.53(\mathrm{~d}, 2 \mathrm{H}, J=8.2 \mathrm{~Hz}) ;{ }^{13} \mathrm{C}-\mathrm{NMR}\left(\mathrm{CDCl}_{3}, 67.8 \mathrm{MHz}\right) \delta 21.3,44.6,52.2,56.5,61.8,71.1$, 113.5, 127.1, 127.2, 127.4, 127.5, 134.9, 143.3, 146.9, 158.6; LRMS $\left(\mathrm{FAB}^{+}\right) \mathrm{m} / z 470\left(\mathrm{MH}^{+}\right)$; HRMS calcd for $\mathrm{C}_{19} \mathrm{H}_{21} \mathrm{NO}_{3} \mathrm{SI} 470.0289$, found 470.0296; IR $\left(\mathrm{CHCl}_{3}, \mathrm{~cm}^{-1}\right)$ 2956, 2932, 2838, $1644,1461,1346,1159,1035$.

5a $(Z):{ }^{1} \mathrm{H}-\mathrm{NMR}\left(\mathrm{CDCl}_{3}, 500 \mathrm{MHz}\right) \delta 2.40(\mathrm{~s}, 3 \mathrm{H}), 2.72-2.78(\mathrm{~m}, 2 \mathrm{H}), 3.78(\mathrm{~s}, 3 \mathrm{H}), 4.07(\mathrm{~s}, 1 \mathrm{H})$, 4.99-5.01 (m, 2H), $6.02(\mathrm{~s}, 1 \mathrm{H}), 6.78(\mathrm{~d}, 2 \mathrm{H}, J=8.9 \mathrm{~Hz}), 7.16(\mathrm{~d}, 2 \mathrm{H}, J=8.9 \mathrm{~Hz}), 7.23(\mathrm{~d}, 2 \mathrm{H}, J=$ $8.2 \mathrm{~Hz}), 7.53(\mathrm{~d}, 2 \mathrm{H}, J=8.2 \mathrm{~Hz}) ;{ }^{13} \mathrm{C}-\mathrm{NMR}\left(\mathrm{CDCl}_{3}, 67.8 \mathrm{MHz}\right) \delta 21.3,42.3,52.8,55.1,63.5,70.3$, 113.7, 127.1, 127.2, 127.4, 127.5, 132.7, 143.4, 147.0, 158.9; LRMS $\left(\mathrm{FAB}^{+}\right) \mathrm{m} / z 470\left(\mathrm{MH}^{+}\right)$; HRMS calcd for $\mathrm{C}_{19} \mathrm{H}_{21} \mathrm{NO}_{3} \mathrm{SI} 470.0289$, found 470.0296; IR $\left(\mathrm{CHCl}_{3}, \mathrm{~cm}^{-1}\right)$ 2956, 2932, 2838, 1644, 1461, 1346, 1159, 1035. 


\section{Preparation of [3-(2-iodo-cyclohexyloxy)-prop-1-ynyl]-benzene (7)}

To a stirred, ice cold suspension of $2.250 \mathrm{~g}(10.00 \mathrm{mmol})$ of $N$-iodosuccinimide in $5 \mathrm{ml}$ of dichloromethane was added a mixture of cyclohexene (840 mg, $10.00 \mathrm{mmol})$ and 1-phenyl-1propyn-3-ol $(1.320 \mathrm{~g}, 10.00 \mathrm{mmol})$ in $5 \mathrm{ml}$ of dichloromethane over $5 \mathrm{~min}$. After warming to room temperature with stirring over $2 \mathrm{~h}, 5 \mathrm{ml}$ of water was added, and the stirring was continued for $1 \mathrm{~h}$. The layers were separated and aqueous layer was extracted with 2 x $60 \mathrm{ml}$ of ethyl acetate. The combined organic extracts were washed with $10 \%$ aqueous $\mathrm{Na}_{2} \mathrm{~S}_{2} \mathrm{O}_{3}(2 \times 10 \mathrm{ml})$ and brine solution, dried over anhydrous $\mathrm{K}_{2} \mathrm{CO}_{3}$, filtered, and concentrated. Chromatography over silica gel using $9 \%$ diethyl ether in hexane afforded the title iodo ether $7(1.171 \mathrm{~g}, 34 \%)$ as an yellow oil.

7: ${ }^{1} \mathrm{H}-\mathrm{NMR}\left(\mathrm{CDCl}_{3}, 500 \mathrm{MHz}\right) \delta 1.26-1.35(\mathrm{~m}, 2 \mathrm{H}), 1.39-1.41(\mathrm{~m}, 2 \mathrm{H}), 1.83(\mathrm{~m}, 1 \mathrm{H}), 2.00$ (dq, $1 \mathrm{H}, J=3.7,10.7 \mathrm{~Hz}), 2.26-2.29(\mathrm{~m}, 1 \mathrm{H}), 2.40-2.42(\mathrm{~m}, 1 \mathrm{H}), 3.66(\mathrm{dt}, 1 \mathrm{H}, J=4.5,8.6 \mathrm{~Hz}), 4.14$ $(\mathrm{dt}, 1 \mathrm{H}, J=4.5,9.8 \mathrm{~Hz}), 4.50(\mathrm{~d}, 2 \mathrm{H}, J=6.4 \mathrm{~Hz}), 7.31-7.32(\mathrm{~m}, 3 \mathrm{H}), 7.44-7.46(\mathrm{~m}, 2 \mathrm{H}) ;{ }^{13} \mathrm{C}-\mathrm{NMR}$ $\left(\mathrm{CDCl}_{3}, 67.8 \mathrm{MHz}\right) \delta 19.1,23.4,25.4,34.8,57.5,81.7,85.4,86.0,128.2,128.3,131.7$; LRMS $\left(\mathrm{FAB}^{+}\right) \mathrm{m} / z 341\left(\mathrm{MH}^{+}\right)$; HRMS calcd for $\mathrm{C}_{15} \mathrm{H}_{18} \mathrm{OI}$ 341.0404, found 341.0407. IR $\left(\mathrm{CHCl}_{3}, \mathrm{~cm}^{-1}\right)$ $3690,3006,1448,1228,1168,1083,775,743$.

\section{Preparation of 3-benzylidene-octahydro-benzofuran $(7 \mathrm{~b}(E)$ and $7 \mathrm{~b}(Z))$}

To a solution of 7 (510 mg, $1.50 \mathrm{mmol})$ in dry methanol (3 ml) was added indium (0) (172 mg, 1.50 mmol) and iodine $(191 \mathrm{mg}, 0.75 \mathrm{mmol})$. The mixture was stirred for $30 \mathrm{~h}$ at room temperature under argon atmosphere. The mixture was evaporated, washed with diethyl ether, filtered through a plug of celite, and concentrated in vacuo. The crude residue was purified by column chromatography $\left(\mathrm{SiO}_{2}\right.$, hexane: ethyl acetate $\left.=9: 1\right)$ to give $7 \mathbf{b}(E)(122 \mathrm{mg}, 38 \%)$ and $7 \mathbf{b}(Z)(61$ $\mathrm{mg}, 19 \%)$.

7b $(E):{ }^{1} \mathrm{H}-\mathrm{NMR}\left(\mathrm{CDCl}_{3}, 500 \mathrm{MHz}\right) \delta 1.53-1.59(\mathrm{~m}, 6 \mathrm{H}), 1.85-1.88(\mathrm{~m}, 1 \mathrm{H}), 2.07-2.09(\mathrm{~m}, 1 \mathrm{H})$, $2.67(\mathrm{~m}, 1 \mathrm{H}), 3.97-4.00(\mathrm{~m}, 1 \mathrm{H}), 4.58-4.61(\mathrm{dd}, 1 \mathrm{H}, J=1.9,13.3 \mathrm{~Hz}), 4.80(\mathrm{dd}, 1 \mathrm{H}, J=1.9,13.3$ $\mathrm{Hz}), 6.30(\mathrm{~m}, 1 \mathrm{H}), 7.12-7.14(\mathrm{~m}, 2 \mathrm{H}), 7.25-7.26(\mathrm{~m}, 3 \mathrm{H}) ;{ }^{13} \mathrm{C}-\mathrm{NMR}\left(\mathrm{CDCl}_{3}, 67.8 \mathrm{MHz}\right) \delta 21.0$, 23.3, 27.5, 27.6, 44.9, 68.8, 78.2, 120.0, 126.3, 127.8, 128.4, 137.3, 146.8; LRMS (EI) $\mathrm{m} / z 214$ $\left(\mathrm{M}^{+}\right)$; HRMS calcd for $\mathrm{C}_{15} \mathrm{H}_{18} \mathrm{O} 214.1358$, found 214.1357. IR $\left(\mathrm{CHCl}_{3}, \mathrm{~cm}^{-1}\right)$ 3008, 1446, 1244, 1182, 1094, 741, 697.

7b $(Z):{ }^{1} \mathrm{H}-\mathrm{NMR}\left(\mathrm{CDCl}_{3}, 500 \mathrm{MHz}\right) \delta 1.53-1.59(\mathrm{~m}, 6 \mathrm{H}), 1.85-1.88(\mathrm{~m}, 1 \mathrm{H}), 2.07-2.09(\mathrm{~m}, 1 \mathrm{H})$, 
2.88-2.91 (m, 1H), 3.92-3.93 (m, 1H), $4.40(\mathrm{dd}, 1 \mathrm{H}, J=1.9,13.4 \mathrm{~Hz}), 4.68(\mathrm{dd}, 1 \mathrm{H}, J=1.9,13.4$ $\mathrm{Hz}), 6.18(\mathrm{~m}, 1 \mathrm{H}), 7.18-7.22(\mathrm{~m}, 2 \mathrm{H}), 7.32-7.33(\mathrm{~m}, 3 \mathrm{H}) ;{ }^{13} \mathrm{C}-\mathrm{NMR}\left(\mathrm{CDCl}_{3}, 67.8 \mathrm{MHz}\right) \delta 20.1$, 24.4, 25.8, 27.7, 41.0, 71.6, 78.2, 119.0, 126.5, 127.7, 128.4, 137.3, 146.8; LRMS (EI) $\mathrm{m} / z 214$ $\left(\mathrm{M}^{+}\right)$; HRMS calcd for $\mathrm{C}_{15} \mathrm{H}_{18} \mathrm{O} 214.1358$, found 214.1358. IR $\left(\mathrm{CHCl}_{3}, \mathrm{~cm}^{-1}\right)$ 3008, 1446, 1244, $1182,1094,741,697$.

\section{Preparation of 4-(tetrahydro-furo[2,3-b]pyran-3-ylidene)-butyronitrile (10a(Z)) and 3-(2-prop-2-} ynyloxytetrahydro-pyran-3-yl)propionitrile (10b)

To a solution of 1 (50 mg, $0.19 \mathrm{mmol})$ in dry methanol (1 ml) was added indium (0) (22 mg, 0.19 $\mathrm{mmol})$, iodine (24 mg, $0.09 \mathrm{mmol})$, and acrylonitrile $(16 \mathrm{mg}, 0.39 \mathrm{mmol})$. The mixture was stirred for $17 \mathrm{~h}$ at room temperature under argon atmosphere. The mixture was evaporated, washed with diethyl ether, filtered through a plug of celite, and concentrated in vacuo. The crude residue was purified by column chromatography $\left(\mathrm{SiO}_{2}\right.$, hexane: ethyl acetate $\left.=10: 1\right)$ to give $10 \mathrm{a}(Z$ and $E)(24$ $\mathrm{mg}, 65 \%), \mathbf{1 0 b}(3 \mathrm{mg}, 7 \%)$, and $\mathbf{1 a}(4 \mathrm{mg}, 8 \%)$ respectively.

10a $(Z):{ }^{1} \mathrm{H}-\mathrm{NMR}\left(\mathrm{CDCl}_{3}, 500 \mathrm{MHz}\right) \delta 1.30-1.33(\mathrm{~m}, 1 \mathrm{H}), 1.57-1.64(\mathrm{~m}, 1 \mathrm{H}), 1.87-1.95(\mathrm{~m}, 1 \mathrm{H})$, 1.97-2.03 (m, 1H), 2.33 (ddd, 2H, $J=6.4,7.0,7.3 \mathrm{~Hz}), 2.44(\mathrm{ddd}, 2 \mathrm{H}, J=6.4,7.0,7.3 \mathrm{~Hz})$, 2.62-2.74 (m, 1H), $3.45(\mathrm{dd}, 1 \mathrm{H}, J=7.2,11.5 \mathrm{~Hz}), 3.86(\mathrm{~d}, 1 \mathrm{H}, J=11.5 \mathrm{~Hz}), 4.50$ (d, $1 \mathrm{H}, J=13.3$ $\mathrm{Hz}), 4.63(\mathrm{~d}, 1 \mathrm{H}, J=13.3 \mathrm{~Hz}), 5.15(\mathrm{~d}, 1 \mathrm{H}, J=3.7 \mathrm{~Hz}), 5.29(\mathrm{ddd}, 1 \mathrm{H}, J=2.1,5.1,7.2 \mathrm{~Hz}) ;{ }^{13} \mathrm{C}-$ $\mathrm{NMR}\left(\mathrm{CDCl}_{3}, 67.8 \mathrm{MHz}\right) \delta 17.3,20.3,22.6,25.2,42.1,64.5,68.8,101.4,115.3,119.1,141.5$; LRMS $\left(\mathrm{FAB}^{+}\right) m / z 194\left(\mathrm{MH}^{+}\right)$; HRMS calcd for $\mathrm{C}_{11} \mathrm{H}_{16} \mathrm{NO}_{2}$ 194.1182, found 194.1172. IR $\left(\mathrm{CHCl}_{3}\right.$, $\left.\mathrm{cm}^{-1}\right)$ 3020, 2946, 2250, 1215, 1036.

10b: ${ }^{1} \mathrm{H}-\mathrm{NMR}\left(\mathrm{CDCl}_{3}, 500 \mathrm{MHz}\right) \delta 1.21(\mathrm{~m}, 1 \mathrm{H}), 1.51-1.67(\mathrm{~m}, 4 \mathrm{H}), 1.87-1.97(\mathrm{~m}, 2 \mathrm{H}), 2.44(\mathrm{~s}$, 1H), 2.43-2.50 (m, 2H), 3.44-3.50 (m, 1H), 3.94-3.98 (m, 1H), 4.32 (d, 2H, J = 2.1 Hz), 4.36 (d, $1 \mathrm{H}, J=6.1 \mathrm{~Hz}) ;{ }^{13} \mathrm{C}-\mathrm{NMR}\left(\mathrm{CDCl}_{3}, 67.8 \mathrm{MHz}\right) \delta: 15.3,23.9,26.8,27.3,38.8,54.6,64.6,74.4$, 79.2, 102.0, 119.8; Anal. calc. for $\mathrm{C}_{11} \mathrm{H}_{15} \mathrm{NO}_{2}$ : H 7.82; C 68.37; N 7.25; found H 7.99; C 68.54; $\mathrm{N}$ 7.25; LRMS $\left(\mathrm{FAB}^{+}\right) \mathrm{m} / z 194\left(\mathrm{MH}^{+}\right)$; HRMS calcd for $\mathrm{C}_{11} \mathrm{H}_{16} \mathrm{NO}_{2}$ 194.1182, found 194.1187. IR $\left(\mathrm{CHCl}_{3}, \mathrm{~cm}^{-1}\right)$ 3306, 3019, 2941, 2250, 2119, 1229, 1041, 635.

\section{Preparation of 4-(tetrahydro-furo[2,3-b]pyran-3-ylidene)-butyric acid ethyl ester (11a $(Z))$.}

To a solution of 1 (133 mg, $0.50 \mathrm{mmol})$ in dry DMF (0.5 ml) was added indium (0) (115 mg, 1.00 
$\mathrm{mmol}$ ), iodine $(127 \mathrm{mg}, 0.50 \mathrm{mmol})$, and acrylic acid ethyl ester (250 mg, $2.50 \mathrm{mmol})$. The mixture was stirred for $17 \mathrm{~h}$ at room temperature under argon atmosphere. The mixture was evaporated, washed with diethylether, filtered through a plug of celite, and concentrated in vacuo. The crude residue was purified by column chromatography $\left(\mathrm{SiO}_{2}, \mathrm{Hexane}: \mathrm{AcOEt}=10: 1\right)$ to give 11a $(Z$ and $E$ ) (42 mg, 35\%), 1a (48 mg, 36\%), $1 \mathbf{b}(7 \mathrm{mg}, 5 \%)$, and $\mathbf{1 c}(6 \mathrm{mg}, 8 \%)$.

$11 \mathrm{a}(Z):{ }^{1} \mathrm{H}-\mathrm{NMR}\left(\mathrm{CDCl}_{3}, 500 \mathrm{MHz}\right) \delta 1.21(\mathrm{t}, 3 \mathrm{H}, J=7.0 \mathrm{~Hz}), 1.25-1.28(\mathrm{~m}, 1 \mathrm{H}), 1.57-1.59(\mathrm{~m}$, 1H), 1.78-1.89 (m, 1H), 1.96-1.99 (m, 1H), 2.22-2.26 (m, 2H), $2.30(\mathrm{q}, 2 \mathrm{H}, J=5.8 \mathrm{~Hz}), 2.60(\mathrm{~m}$, $1 \mathrm{H}), 3.42(\mathrm{~d}, 1 \mathrm{H}, J=9.2 \mathrm{~Hz}), 3.48(\mathrm{q}, 2 \mathrm{H}, J=7.0 \mathrm{~Hz}), 3.84(\mathrm{~d}, 1 \mathrm{H}, J=9.2 \mathrm{~Hz}), 4.48(\mathrm{~d}, 1 \mathrm{H}, J=$ $13.1 \mathrm{~Hz}), 4.63(\mathrm{~d}, 1 \mathrm{H}, J=13.1 \mathrm{~Hz}), 5.13(\mathrm{~d}, 1 \mathrm{H}, J=4.0 \mathrm{~Hz}), 5.21(\mathrm{~m}, 1 \mathrm{H}) ;{ }^{13} \mathrm{C}-\mathrm{NMR}\left(\mathrm{CDCl}_{3}, 67.8\right.$ MHz) $\delta 14.1,20.2,22.5,24.7,33.9,41.8,60.3,64.4,68.9,101,117,143.0,171.0 ;$ LRMS $_{\left(\mathrm{FAB}^{+}\right)}$ $m / z 240\left(\mathrm{M}^{+}\right)$; HRMS calcd for $\mathrm{C}_{13} \mathrm{H}_{20} \mathrm{O}_{4}$ 240.1361, found: 240.11359; IR $\left(\mathrm{CHCl}_{3}, \mathrm{~cm}^{-1}\right) 3156,2985$, 2942, 2869, 1725, 1463, 1267, 1180, 1095, 1033.

Preparation of $(2 R, 3 S)-$ and $(2 S, \quad 3 R)-3-I o d o-2-\{(S)-1-m e t h y l-p r o p-2-y n y l o x y\}-$ tetrahydropyran (12 and 13)

To a stirred, ice cold suspension of $4.012 \mathrm{~g}(17.83 \mathrm{mmol})$ of $N$-iodosuccinimide in $15 \mathrm{ml}$ of dichloromethane was added a mixture of 3,4-dihydro-2H-pyran (1.000 g, $11.89 \mathrm{mmol})$ and $(S)-(-)$ 3-butyn-2-ol (917 mg, $13.07 \mathrm{mmol})$ in $10 \mathrm{ml}$ of dichloromethane over $5 \mathrm{~min}$. After warming to room temperature with stirring over $2 \mathrm{~h}, 15 \mathrm{ml}$ of water was added, and the stirring was continued for $1 \mathrm{~h}$. The layers were separated and aqueous layer extracted with 2 x $60 \mathrm{ml}$ of ethyl acetate. The combined organic extracts were washed with $10 \%$ aqueous $\mathrm{Na}_{2} \mathrm{~S}_{2} \mathrm{O}_{3}(2 \times 10 \mathrm{ml})$ and brine solution, dried over anhydrous $\mathrm{K}_{2} \mathrm{CO}_{3}$, filtrated, and concentrated. Chromatography over silica gel using $9 \%$ diethyl ether in hexane afforded the title iodo ethers $\mathbf{1 2}(1.493 \mathrm{~g}, 45 \%)$ and $\mathbf{1 3}(1.243 \mathrm{~g}, 37 \%)$ respectively as colorless oil.

12: ${ }^{1} \mathrm{H}$ NMR $(\mathrm{CDCl} 3,500 \mathrm{MHz}) \delta 1.48(\mathrm{~d}, 3 \mathrm{H}, J=6.7 \mathrm{~Hz}), 1.57-1.62(\mathrm{~m}, 1 \mathrm{H}), 1.76-1.78(\mathrm{~m}, 1 \mathrm{H})$, 2.00-2.04 (m, 1H), 2.36-2.39 (m, 1H), $2.47(\mathrm{~d}, 1 \mathrm{H}, J=2.2 \mathrm{~Hz}), 3.58-3.62(\mathrm{~m}, 1 \mathrm{H}), 4.07-4.12(\mathrm{~m}$, $2 \mathrm{H}), 4.47(\mathrm{dq}, 1 \mathrm{H}, J=2.2,6.7 \mathrm{~Hz}), 4.79(\mathrm{~d}, 1 \mathrm{H}, J=2.2 \mathrm{~Hz}) ;{ }^{13} \mathrm{C} \mathrm{NMR}\left(\mathrm{CDCl}_{3}, 67.8 \mathrm{MHz}\right) \delta 21.8$, 25.3, 29.3, 32.6, 63.8, 64.2, 72.7, 83.7, 101.6; $[\alpha]_{\mathrm{D}}{ }^{26}=+24.1$ (c 1.15, $\left.\mathrm{CHCl}_{3}\right)$; Anal. calcd for $\mathrm{C}_{9} \mathrm{H}_{13} \mathrm{O}_{2} \mathrm{I}: \mathrm{H}, 4.68$; C, 38.57; I, 45.32, found: H, 4.50; C, 38.67; I, 45.48; LRMS (EI) m/z $280\left(\mathrm{M}^{+}\right)$; HRMS (EI) calcd for $\mathrm{C}_{9} \mathrm{H}_{13} \mathrm{O}_{2} \mathrm{I}\left(\mathrm{M}^{+}\right)$279.9962, found 279.9951; IR ( $\left.\mathrm{cm}^{-1}, \mathrm{CHCl}_{3}\right)$ 3307, 2952, 2857 , 
1439, 1375, 1121, 1095, 1067.

13: ${ }^{1} \mathrm{H}$ NMR $\left(\mathrm{CDCl}_{3}, 500 \mathrm{MHz}\right) \delta 1.47(\mathrm{dd}, 3 \mathrm{H}, J=2.2,6.7 \mathrm{~Hz}), 1.55-1.58(\mathrm{~m}, 1 \mathrm{H}), 1.81-1.82$ (m, 1H), 2.02-2.05 (m, 1H), 2.34-2.37 (m, 1H), $2.44(\mathrm{~d}, 1 \mathrm{H}, J=2.2 \mathrm{~Hz}), 3.60-3.63(\mathrm{~m}, 1 \mathrm{H})$, 3.90-3.93 (m, 1H), 4.08-4.11 (m, 1H), $4.55(\mathrm{dq}, 1 \mathrm{H}, J=2.2,6.7 \mathrm{~Hz}), 4.99-5.00(\mathrm{~m}, 1 \mathrm{H}) ;{ }^{13} \mathrm{C} \mathrm{NMR}$ $\left(\mathrm{CDCl}_{3}, 67.8 \mathrm{MHz}\right) \delta 21.9,25.1,28.6,32.1,61.6,63.3,73.5,82.7,99.3 ;[\alpha]_{\mathrm{D}}{ }^{28}=-127.6(c 1.12$, $\mathrm{CHCl}_{3}$ ); Anal. calcd. for $\mathrm{C}_{9} \mathrm{H}_{13} \mathrm{O}_{2} \mathrm{I}$ : H, 4.68; C, 38.57; I, 45.32, found H, 4.50; C, 38.67; I, 45.48; IR $\left(\mathrm{cm}^{-1}, \mathrm{CHCl}_{3}\right)$ 3306, 2949, 2857, 1438, 1374, 1120, 1094, 1066.

\section{(2S, 3R)-3-Iodo-2-\{(R)-1-methyl-prop-2-ynyloxy $\}$-tetrahydropyran (14)}

From $(R)-(+)-3$-butyn-2-ol using the procedure substantially as described above for preparation of compound 14 and 15 were obtained $47 \%$ and $46 \%$ yields respectively as colorless oil.

14: $[\alpha]_{\mathrm{D}}{ }^{28}=-24.1$ ( c 1.42, $\mathrm{CHCl}_{3}$ ); LRMS (EI) $\mathrm{m} / \mathrm{z} 280\left(\mathrm{M}^{+}\right)$; HRMS (EI) calcd for $\mathrm{C}_{9} \mathrm{H}_{13} \mathrm{O}_{2} \mathrm{I}\left(\mathrm{M}^{+}\right)$ 279.9962, found 279.9958. Other spectral data of compounds $\mathbf{1 4}$ were in accordance with those of 12.

\section{(2R, 3S)-3-Iodo-2-\{(R)-1-methyl-prop-2-ynyloxy $\}$-tetrahydropyran (15)}

15: $[\alpha]_{\mathrm{D}}{ }^{30}=+131.0^{\circ}\left(c 1.06, \mathrm{CHCl}_{3}\right)$; LRMS (EI) $\mathrm{m} / z, 280\left(\mathrm{M}^{+}\right)$; HRMS (EI) calcd for $\mathrm{C}_{9} \mathrm{H}_{13} \mathrm{O}_{2} \mathrm{I}\left(\mathrm{M}^{+}\right)$ 279.9962, found 279.9956. Other spectral data of compounds $\mathbf{1 5}$ were in accordance with those of 13.

\section{(2S, 3aS, 7aR)-2-Methyl-3-methylene-hexahydro-furo[2,3-b]pyran (12a)}

To solution of 12 (1.278 g, $4.57 \mathrm{mmol})$ in dry methanol (3 ml) was added indium(0) (525 mg, 4.57 $\mathrm{mmol})$ and iodine $(580 \mathrm{mg}, 2.285 \mathrm{mmol})$. The mixture was stirred for $30 \mathrm{~h}$ at room temperature under argon atmosphere. The mixture was evaporated, washed by diethyl ether, filtrated by celite pad (diethyl ether as eluent), and concentrated in vacuo. The crude residue was purified by column chromatography $\left(\mathrm{SiO}_{2}\right.$, hexane $:$ diethylether $\left.=9: 1\right)$ to give 12a $(352 \mathrm{mg}, 50 \%)$ as colorless oil.

12a: ${ }^{1} \mathrm{H}$ NMR $\left(\mathrm{CDCl}_{3}, 500 \mathrm{MHz}\right) \delta 1.29(\mathrm{~d}, 1 \mathrm{H}, J=1.8,13.5 \mathrm{~Hz}), 1.33(\mathrm{~d}, 3 \mathrm{H}, J=6.7 \mathrm{~Hz})$, 1.57-1.67 (m, 1H), 1.86-1.93 (m, 1H), $2.01(\mathrm{~d}, 1 \mathrm{H}, J=11.6 \mathrm{~Hz}), 2.72(\mathrm{~d}, J=3.7 \mathrm{~Hz}), 3.42(\mathrm{dt}, 1 \mathrm{H}$, $J=1.8,11.6 \mathrm{~Hz}), 3.86(\mathrm{~d}, 1 \mathrm{H}, J=9.6 \mathrm{~Hz}), 4.76-4.78(\mathrm{~m}, 1 \mathrm{H}), 4.92(\mathrm{~m}, 1 \mathrm{H}), 5.00(\mathrm{~m}, 1 \mathrm{H}), 5.14(\mathrm{~d}$, $1 \mathrm{H}, J=3.7 \mathrm{H}) ;{ }^{13} \mathrm{C} \mathrm{NMR}\left(\mathrm{CDCl}_{3}, 67.8 \mathrm{MHz}\right) \delta 20.2,21.6,22.6,42.0,64.6,77.7,100.8,103.9$, 
152.1; LRMS (EI) $m / z 154\left(\mathrm{M}^{+}\right)$; HRMS (EI) calcd for $\mathrm{C}_{9} \mathrm{H}_{14} \mathrm{O}_{2}\left(\mathrm{M}^{+}\right)$154.0994, found 154.0991; $[\alpha]_{\mathrm{D}}{ }^{26}=-120.4\left(c 1.02, \mathrm{CHCl}_{3}\right) ; \mathrm{IR}\left(\mathrm{cm}^{-1}, \mathrm{CHCl}_{3}\right) 3011,2931,1453,1370,1119,1075,1033$.

(2S, 3aR, 7aS)-2-Methyl-3-methylene-hexahydro-furo[2,3-b]pyran (13a)

13a: ${ }^{1} \mathrm{H} \mathrm{NMR}\left(\mathrm{CDCl}_{3}, 500 \mathrm{MHz}\right) \delta 1.29-1.33(\mathrm{~m}, 1 \mathrm{H}), 1.42(\mathrm{~d}, 1 \mathrm{H}, J=6.4 \mathrm{~Hz}), 1.56-1.65(\mathrm{~m}$, $1 \mathrm{H}), 1.85-1.93(\mathrm{~m}, 1 \mathrm{H}), 1.97-2.00(\mathrm{~m}, 1 \mathrm{H}), 2.71(\mathrm{~s}, 1 \mathrm{H}), 3.43(\mathrm{dt}, 1 \mathrm{H}, J=2.5,10.5 \mathrm{~Hz}), 3.84(\mathrm{~d}$, $1 \mathrm{H}, J=11.6 \mathrm{~Hz}), 4.64(\mathrm{~m}, 1 \mathrm{H}), 4.96(\mathrm{dt}, 2 \mathrm{H}, J=2.5,10.5 \mathrm{~Hz}), 5.09(\mathrm{~d}, 1 \mathrm{H}, J=6.4 \mathrm{~Hz}) ;{ }^{13} \mathrm{C} \mathrm{NMR}$ $\left(\mathrm{CDCl}_{3}, 67.8 \mathrm{MHz}\right) \delta 20.6,22.1,22.5,42.7,64.2,77.7,100.5,103.9$, 151.9; Anal. calcd. for $\mathrm{C}_{9} \mathrm{H}_{14} \mathrm{O}_{2}: \mathrm{H}, 9.16 ; \mathrm{C}, 70.08$, found $\mathrm{H}, 9.39 ; \mathrm{C}, 69.87 ;[\alpha]_{\mathrm{D}}^{22}=+26.3\left(c 1.09, \mathrm{CHCl}_{3}\right)$; IR $\left(\mathrm{cm}^{-1}\right.$, $\left.\mathrm{CHCl}_{3}\right)$ 3012, 2946, 1453, 1371, 1117, 1074, 1036.

\section{(2R, 3aR, 7aS)-2-Methyl-3-methylene-hexahydro-furo[2,3-b]pyran (14a)}

From 14 and 15 using the procedure substantially as described above for preparation of compound 14a and 15a were obtained $66 \%$ and $62 \%$ yields respectively as colorless oil.

14a: LRMS (EI) $m / z, 154\left(\mathrm{M}^{+}\right)$; HRMS (EI) calcd for $\mathrm{C}_{9} \mathrm{H}_{14} \mathrm{O}_{2}\left(\mathrm{M}^{+}\right)$154.0994, found 154.0995 $[\alpha]_{\mathrm{D}}^{29}=+123.9\left(c 1.37, \mathrm{CHCl}_{3}\right)$. Other spectral data of $\mathbf{1 4 a}$ were in accordance with those of $\mathbf{1 2 a}$.

(2R, 3aS, 7aR)-2-Methyl-3-methylene-hexahydro-furo[2,3-b]pyran (15a)

15a: LRMS (EI) $m / z 154\left(\mathrm{M}^{+}\right)$; HRMS (EI) calcd for $\mathrm{C}_{9} \mathrm{H}_{14} \mathrm{O}_{2}\left(\mathrm{M}^{+}\right)$154.0994, found: 154.0989 $[\alpha]_{\mathrm{D}}^{30}=-27.0\left(c 1.05, \mathrm{CHCl}_{3}\right)$. Other spectral data of $\mathbf{1 5 a}$ were in accordance with those of $\mathbf{1 3 a}$.

\section{(2S, 3R, 3aS, 7aR)-2-Methyl-hexahydro-furo[2,3-b]pyran-3-ol (12b)}

A stream of ozone was dispersed into solution of 12a (409 mg, $2.66 \mathrm{mmol})$ in methanol(3 ml) at -78

${ }^{\circ} \mathrm{C}$ for $30 \mathrm{~min}$. The resulting blue solution was purged with oxygene until the solution was clear, then to the solution sodium borohydride $(58 \mathrm{mg}, 1.81 \mathrm{mmol})$ was added. The reaction mixture was stirred for an additional $15 \mathrm{~min}$ at $0{ }^{\circ} \mathrm{C}$, and then the reaction was quenched with $10 \%$ aqueous citric acid $(1.5 \mathrm{ml})$. The resulting mixture was concentrated under reduced pressure, and the residue was partitioned between diethyl ether and brine. The layers were separated, and the aqueous layer was extracted with diethyl ether $(2 \times 60 \mathrm{ml})$. The combined organic layers were dried over anhydrous $\mathrm{K}_{2} \mathrm{CO}_{3}$ and concentrated carefully under reduced pressure. The resulting residue was chromatographed over silica gel using $25 \%$ hexane in diethyl ether as the eluent to furnish the title 
alcohol 12b (326 mg, 77\%) as yellow oil.

12b: ${ }^{1} \mathrm{H}$ NMR $\left(\mathrm{CDCl}_{3}, 500 \mathrm{MHz}\right) \delta 1.22(\mathrm{dd}, 3 \mathrm{H}, J=2.2,6.4 \mathrm{~Hz}), 1.45-1.48(\mathrm{~m}, 1 \mathrm{H}), 1.83-1.95$ $(\mathrm{m}, 2 \mathrm{H}), 2.11(\mathrm{~m}, 2 \mathrm{H}), 2.36(\mathrm{~s}, 1 \mathrm{H}), 3.50(\mathrm{dt}, 1 \mathrm{H}, J=2.2,11.3 \mathrm{~Hz}), 3.87(\mathrm{~s}, 1 \mathrm{H}), 3.94(\mathrm{~d}, 1 \mathrm{H}, J=$ $11.7 \mathrm{~Hz}), 4.33(\mathrm{q}, 1 \mathrm{H}, J=6.4 \mathrm{~Hz}), 5.07(\mathrm{~d}, 1 \mathrm{H}, J=3.4 \mathrm{~Hz}) ;{ }^{13} \mathrm{C} \mathrm{NMR}\left(\mathrm{CDCl}_{3}, 67.8 \mathrm{MHz}\right) \delta 20.1$, 20.2, 22.7, 39.7, 64.0, 79.4, 84.4, 102.3; LRMS (EI) $m / z 159\left(\mathrm{MH}^{+}\right)$, HRMS (EI) calcd for $\mathrm{C}_{8} \mathrm{H}_{15} \mathrm{O}_{3}$ $\left(\mathrm{MH}^{+}\right)$159.1021, found 159.1022; $[\alpha]_{\mathrm{D}}^{28}=-14.5\left(c\right.$ 1.06, $\left.\mathrm{CHCl}_{3}\right) ; \mathrm{IR}\left(\mathrm{cm}^{-1}, \mathrm{CHCl}_{3}\right) 3542,3014$, 2971, 1450, 1375, 1121, 1096, 1040.

\section{(2S, 3S, 3aR, 7aS)-2-Methyl-hexahydro-furo[2,3-b]pyran-3-ol (13b)}

From 13a $(385 \mathrm{mg}, 2.50 \mathrm{mmol})$ using the procedure substantially as described above for preparation of compound 13b was obtained as yellow oil (262 mg, 66\%).

13b: ${ }^{1} \mathrm{H} \mathrm{NMR}\left(\mathrm{CDCl}_{3}, 500 \mathrm{MHz}\right) \delta 1.35(\mathrm{~d}, 3 \mathrm{H}, J=6.4 \mathrm{~Hz}), 1.44-1.46(\mathrm{~m}, 1 \mathrm{H}), 1.91-1.96(\mathrm{~m}$, 1H), $2.06(\mathrm{~d}, 1 \mathrm{H}, J=3.7 \mathrm{~Hz}), 2.22-2.28(\mathrm{~m}, 2 \mathrm{H}), 3.44-3.48(\mathrm{~m}, 1 \mathrm{H}), 3.94-3.95(\mathrm{~m}, 2 \mathrm{H}), 4.14-4.16$ $(\mathrm{m}, 1 \mathrm{H}), 4.98(\mathrm{~d}, 1 \mathrm{H}, J=3.7 \mathrm{~Hz}) ;{ }^{13} \mathrm{C} \mathrm{NMR}\left(\mathrm{CDCl}_{3}, 67.8 \mathrm{MHz}\right) \delta 14.9,21.1,22.8,42.2,64.4,76.1$, 80.9, 102.7; LRMS (FAB) $m / z, 159\left(\mathrm{MH}^{+}\right)$, HRMS (FAB) calcd for $\mathrm{C}_{8} \mathrm{H}_{15} \mathrm{O}_{3}\left(\mathrm{MH}^{+}\right)$159.1021, found 159.1024; $[\alpha]_{\mathrm{D}}^{25}=+15.3\left(c 1.09, \mathrm{CHCl}_{3}\right)$; IR $\left(\mathrm{cm}^{-1}, \mathrm{CHCl}_{3}\right) 3531,3016,2959,1446,1383,1121$, $1075,1041$.

\section{(2R, 3S, 3aR, 7aS)-2-Methyl-hexahydro-furo[2,3-b]pyran-3-ol (14b) and (15b)}

From 14a and 15a using the procedure substantially as described above for preparation of compound 14b and 15b were obtained $88 \%$ and $64 \%$ respectively as colorless oil.

14b: LRMS (EI) $m / z 159\left(\mathrm{MH}^{+}\right)$, HRMS (EI) calcd for $\mathrm{C}_{8} \mathrm{H}_{15} \mathrm{O}_{3}\left(\mathrm{MH}^{+}\right)$159.1021, found 159.1026, $[\alpha]_{\mathrm{D}}{ }^{20}=+14.1\left(c 1.00, \mathrm{CHCl}_{3}\right)$. Other spectral data of compound $\mathbf{1 4 b}$ was in accordance with those of $\mathbf{1 2 b}$.

(2R, 3R, 3aS, 7aR)-2-Methyl-hexahydro-furo[2,3-b]pyran-3-ol (15b)

15b: LRMS (EI) $m / z 159\left(\mathrm{MH}^{+}\right)$, HRMS (EI) calcd for $\mathrm{C}_{8} \mathrm{H}_{15} \mathrm{O}_{3}\left(\mathrm{MH}^{+}\right)$159.1021, found 159.1018, $[\alpha]_{\mathrm{D}}{ }^{30}=-15.7\left(c 1.23, \mathrm{CHCl}_{3}\right)$. Other spectral data of compound $\mathbf{1 5 b}$ was in accordance with those of $13 b$. 
carbamic acid (2S, 3R, 3aS, 7aR)-2-methyl-hexahydro-furo[2,3-b]pyran-3-yl ester (12d)

To the solution of $\mathbf{1 2 b}(57 \mathrm{mg}, 0.38 \mathrm{mmol})$ in dry dichloromethane $(1.4 \mathrm{ml})$ was added 4nitrophenyl- chloroformate $(108 \mathrm{mg}, 0.54 \mathrm{mmol})$ and triethylamine (108 mg, $1.07 \mathrm{mmol})$. The mixture was stirred for $22 \mathrm{~h}$ at room temperature. The mixture was diluted with ethyl acetate, extracted with satd. aqueous $\mathrm{NaHCO}_{3}(10 \times 5 \mathrm{ml})$ and washed with brine. The organic layer was dried with anhydrous $\mathrm{MgSO}_{4}$, filtrated, and concentrated under reduced pressure. The residue was chromatographed over silica gel using 50\% ethyl acetate in hexane as the eluent to furnish (100 mg, $87 \%$ ) the activated alcohol $12 \mathrm{c}$ as an yellow oil. To the solution of the activated alcohol 12c (29 $\mathrm{mg}, 0.09 \mathrm{mmol})$ in dichloromethane $(0.4 \mathrm{ml})$ was added amine $16(30 \mathrm{mg}, 0.075 \mathrm{mmol})$ and triethylamine $(23 \mathrm{mg}, 0.22 \mathrm{mmol})$. The mixture was stirred for $22 \mathrm{~h}$ at room temperature. The mixture was concentrated under reduced pressure, diluted with ethyl acetate, extracted with saturated aqueous $\mathrm{NaHCO}_{3}(10 \times 5 \mathrm{ml})$ and washed with brine. The organic layer was dried with anhydrous $\mathrm{MgSO}_{4}$, filtrated, and concentrated under reduced pressure. The residue was chromatographed over silica gel using 50\% hexane in ethyl acetate as the eluent to furnish $\mathbf{1 2 d}$ (29 $\mathrm{mg}, 67 \%$ ) the title product as white powder.

12d: ${ }^{1} \mathrm{H}$ NMR $\left(\mathrm{CDCl}_{3}, 500 \mathrm{MHz}\right) \delta 1.12-1.51(\mathrm{~m}, 26 \mathrm{H}), 1.66-2.17(\mathrm{~m}, 7 \mathrm{H}), 2.57-2.65(\mathrm{~m}, 2 \mathrm{H})$, 2.90-3.09 (m, 3H), 3.27-3.46 (m, 2H), 3.75-3.78 (m, 1H), $3.90(\mathrm{~s}, 1 \mathrm{H}), 4.76-4.77(\mathrm{~m}, 1 \mathrm{H}), 5.10$ $(\mathrm{m}, 1 \mathrm{H}), 5.49-5.51(\mathrm{~m}, 1 \mathrm{H}), 5.89(\mathrm{~s}, 1 \mathrm{H}), 7.17-7.26(\mathrm{~m}, 5 \mathrm{H}) ;{ }^{13} \mathrm{C} \mathrm{NMR}\left(\mathrm{CDCl}_{3}, 67.8 \mathrm{MHz}\right) \delta 19.7$, 19.7, 20.6, 22.2, 25.9, 26.1, 28.7, 30.7, 33.4, 35.5, 35.9, 39.4, 51.0,56.2, 58.8, 59.4, 63.4, 70.5, 71.3, 79.5, 100.8, 126.2, 128.3, 129.2, 138.3, 156.4, 173.6; LRMS (FAB) $m / z 586\left(\mathrm{MH}^{+}\right)$; HRMS (FAB) calcd for $\mathrm{C}_{33} \mathrm{H}_{52} \mathrm{~N}_{3} \mathrm{O}_{6}\left(\mathrm{MH}^{+}\right)$586.3855, found 586.3843; $[\alpha]_{\mathrm{D}}{ }^{28}=-88.3\left(c 1.05, \mathrm{CHCl}_{3}\right)$; IR $\left(\mathrm{cm}^{-1}\right.$, $\left.\mathrm{CHCl}_{3}\right)$ 3430, 3008, 2928, 2859, 1712, 1670, 1244, 1094, 1052, 768, 736, 660.

\section{[(1S, 2R)-1-Benzyl-3-(3-tert-butylcarbamoyl-octahydro-isoquinolin-2-yl)-2-hydroxy-propyl]-} carbamic acid (2S, 3S, 3aR, 7aS)-2-methyl-hexahydro-furo[2,3-b]pyran-3-yl ester (13d)

Dry toluene $(1.8 \mathrm{ml}), \mathbf{1 3 b}(30 \mathrm{mg}, 0.19 \mathrm{mmol}), \mathrm{KOH}(0.5 \mathrm{mg}, 0.01 \mathrm{mmol})$, and 1,1'-carbonyl diimidazole $(184 \mathrm{mg}, 1.13 \mathrm{mmol}$ ) were added to a $10 \mathrm{ml}$ round-bottomed flask fitted with a dry argon inlet and magnet stirrer and heated to $60{ }^{\circ} \mathrm{C}$ with stirring for $3 \mathrm{~h}$. Amine 16 (15 mg, 0.038 mmol), DMAP (0.9 mg, $0.007 \mathrm{mmol})$, and triethylamine (12 mg, $0.112 \mathrm{mmol})$ was added. The solution was left to stir at $110{ }^{\circ} \mathrm{C}$ for a further $18 \mathrm{~h}$. The clear mixture was left to cool. The 
reaction was concentrated in vacuo, dissolved in ethyl acetate $(60 \mathrm{ml})$, and washed with saturated aqueous $\mathrm{NaHCO}_{3}(5 \times 10 \mathrm{ml})$. The solution was dried with anhydrous $\mathrm{MgSO}_{4}$ and concentrated in vacuo. The resulting residue was chromatographed over silica gel using $33 \%$ hexane in diethyl ether as the eluent to furnish $\mathbf{1 3 d}(13 \mathrm{mg}, 50 \%)$ the title carbamate as white powder.

13d: ${ }^{1} \mathrm{H}$ NMR $\left(\mathrm{CDCl}_{3}, 500 \mathrm{MHz}\right) \delta 1.00-1.52(\mathrm{~m}, 26 \mathrm{H}), 1.60-2.18(\mathrm{~m}, 7 \mathrm{H}), 2.25-2.30(\mathrm{~m}, 1 \mathrm{H})$, 2.30-2.42 (m, 1H), 2.64-2.72 (m, 1H), 2.78-3.02 (m, 2H), 3.32-3.91 (m, 1H), 3.76-3.88 (m, 1H), 3.90-4.00 (brs, 1H), 4.18-4.24 (m, 1H), 4.96 (d, 1H, J = 2.1 Hz), 5.17 (d, 1H, J = 3.7 Hz), $5.22(\mathrm{t}$, $1 \mathrm{H}, J=1.8 \mathrm{~Hz}), 5.88(\mathrm{~s}, 1 \mathrm{H}), 7.18-7.39(\mathrm{~m}, 5 \mathrm{H})$; LRMS (FAB) $m / z 586\left(\mathrm{MH}^{+}\right)$; HRMS (FAB) calcd for $\mathrm{C}_{33} \mathrm{H}_{52} \mathrm{~N}_{3} \mathrm{O}_{6}\left(\mathrm{MH}^{+}\right)$586.3855, found 586.3849. The other spectral data could not be measured because of the low yield of the product 13d.

[(1S, 2R)-1-Benzyl-3-(3-tert-butylcarbamoyl-octahydro-isoquinolin-2-yl)-2-hydroxy-propyl]carbamic acid (2R, 3S, 3aR, 7aS)-2-methyl-hexahydro-furo[2,3-b]pyran-3-yl ester (14d)

14d: ${ }^{1} \mathrm{H}$ NMR $\left(\mathrm{CDCl}_{3}, 500 \mathrm{MHz}\right) \delta 1.12-1.51(\mathrm{~m}, 26 \mathrm{H}), 1.66-1.81(\mathrm{~m}, 4 \mathrm{H}), 2.25-2.38(\mathrm{~m}, 3 \mathrm{H})$, 2.55-2.70 (m, 2H), 2.90-2.99 (m, 3H), 3.38-3.49 (m, 2H), $3.83(\mathrm{~s}, 1 \mathrm{H}), 3.93(\mathrm{~s}, 1 \mathrm{H}), 4.73(\mathrm{~s}, 1 \mathrm{H})$, $5.09(\mathrm{~s}, 2 \mathrm{H}), 5.86(\mathrm{~s}, 1 \mathrm{H}), 7.23-7.29(\mathrm{~m}, 5 \mathrm{H}) ;{ }^{13} \mathrm{C} \mathrm{NMR}\left(\mathrm{CDCl}_{3}, 67.8 \mathrm{MHz}\right) \delta 19.7,20.1,20.7$, 22.5, 25.9, 26.0, 28.7, 30.7, 30.8, 33.3, 35.5, 35.8, 39.0, 56.1,58.9, 59.9, 63.2, 70.4, 71.1, 79.6, 79.8, 100.7, 126.4, 128.5, 129.4, 138.3, 156.4, 169.0; LRMS (FAB) $m / z .586\left(\mathrm{MH}^{+}\right)$; HRMS (FAB) calcd for $\mathrm{C}_{33} \mathrm{H}_{52} \mathrm{~N}_{3} \mathrm{O}_{6}\left(\mathrm{MH}^{+}\right)$586.3856, found 586.3870; $[\alpha]_{\mathrm{D}}{ }^{29}=-40.3\left(c\right.$ 1.00, $\left.\mathrm{CHCl}_{3}\right)$; IR $\left(\mathrm{cm}^{-1}, \mathrm{CHCl}_{3}\right)$ 3430, 3008, 2929, 2859, 1723, 1670, 1249, 1094, 1052, 766, 748, 650.

\section{\{(1S,2R)-3-[(4-Amino-benzenesulfonyl)-isobutyl-amino]-1-benzyl-2-hydroxy-propyl\}-} carbamic acid (2S, 3R, 3aS, 7aR)-2-methyl-hexahydro-furo[2,3-b]pyran-3-yl ester (12e)

To the solution of the activated alcohol 12c $(30 \mathrm{mg}, 0.09 \mathrm{mmol})$ in $\mathrm{CH}_{2} \mathrm{Cl}_{2}(0.4 \mathrm{ml})$ was added amine 17 (30 mg, $0.077 \mathrm{mmol}$ ) and triethylamine (23 mg, $0.23 \mathrm{mmol})$. The mixture was stirred for $37 \mathrm{~h}$ at room temperature. The mixture was concentrated under reduced pressure, diluted with ethyl acetate, extracted with saturated aqueous $\mathrm{NaHCO}_{3}(10 \times 5 \mathrm{ml})$ and washed with brine. The organic layer was dried with anhydrous $\mathrm{MgSO}_{4}$, filtrated, and concentrated under reduced pressure. The residue was chromatographed over silica gel using $25 \%$ hexane in ethyl acetate as the eluent to furnish 12e (18 $\mathrm{mg}, 42 \%)$ as yellow oil. 
12e: ${ }^{1} \mathrm{H}$ NMR $\left(\mathrm{CDCl}_{3}, 500 \mathrm{MHz}\right) \delta$ 0.87-0.92 (m, 9H), $1.24(\mathrm{~s}, 4 \mathrm{H}), 1.46(\mathrm{~s}, 1 \mathrm{H}), 1.54(\mathrm{~s}, 1 \mathrm{H}), 1.82$ (s, 1H), 2.20 (s, 1H), 2.80-3.11 (m, 6H), 3.41-3.47 (m, 1H), 3.72-3.87 (m, 4H), 4.18 (s, 2H), 4.73 $(\mathrm{s}, 1 \mathrm{H}), 4.96(\mathrm{~s}, 1 \mathrm{H}), 5.05(\mathrm{~s}, 1 \mathrm{H}), 6.68(\mathrm{~d}, 2 \mathrm{H}, J=8.5 \mathrm{~Hz}), 7.22-7.26(\mathrm{~m}, 5 \mathrm{H}), 7.54(\mathrm{~d}, J=8.5 \mathrm{~Hz}$, $2 \mathrm{H}) ;{ }^{13} \mathrm{C} \mathrm{NMR}\left(\mathrm{CDCl}_{3}, 67.8 \mathrm{MHz}\right) \delta 19.7,19.7,20.1,22.3,27.2,35.6,39.1,53.8,54.8,58.8,63.3$, 72.7, 79.9, 100.9, 114.0, 126.0, 126.4, 128.4, 129.3, 129.5, 133.7, 137.5, 150.7; LRMS (FAB) m/z: $576\left(\mathrm{MH}^{+}\right)$; HRMS (FAB) calcd for $\mathrm{C}_{29} \mathrm{H}_{42} \mathrm{~N}_{3} \mathrm{O}_{7} \mathrm{~S}\left(\mathrm{MH}^{+}\right)$576.2743, found 576.2725; $[\alpha]_{\mathrm{D}}{ }^{24}=-1.5(c$ 1.11, $\left.\mathrm{CHCl}_{3}\right)$; IR $\left(\mathrm{cm}^{-1}, \mathrm{CHCl}_{3}\right) 3417,1715,1338,1234,1151,1093,765,744,668$.

\section{\{(1S,2R)-3-[(4-Amino-benzenesulfonyl)-isobutyl-amino]-1-benzyl-2-hydroxy-propyl\}-} carbamic acid (2R, 3S, 3aR, 7aS)-2-methyl-hexahydro-furo[2,3-b]pyran-3-yl ester (14e) 14e: ${ }^{1} \mathrm{H} \mathrm{NMR}\left(\mathrm{CDCl}_{3}, 500 \mathrm{MHz}\right) \delta 0.84-0.92(\mathrm{~m}, 9 \mathrm{H}), 1.07-1.40(\mathrm{~m}, 4 \mathrm{H}), 1.55-1.57$ (brs, $\left.1 \mathrm{H}\right)$, $1.58-1.90$ (m, 2H), 2.25-2.31 (brs, 1H), 2.75-3.21 (m, 6H), 3.44 (t, 1H, J = 9.7 Hz), 3.81-3.94 (m, 4H), 4.13-4.18 (m, 2H), 4.75-4.78 (brs, 1H), 5.05 (s, 1H), 6.68 (d, 2H, J = 8.5 Hz), 7.21-7.26 (m, 5H), $7.54(\mathrm{~d}, J=8.5 \mathrm{~Hz}, 2 \mathrm{H}) ;{ }^{13} \mathrm{C} \mathrm{NMR}\left(\mathrm{CDCl}_{3}, 67.8 \mathrm{MHz}\right) \delta 19.7,19.7,20.1,22.3,27.2,35.5$, 39.0, 53.8, 54.7, 58.8, 63.1, 72.3, 80.2, 100.4, 107.8, 112.6, 116.6, 128.4, 129.4, 129.5, 136.7, 138.9, 154.7; LRMS (FAB) $m / z 576\left(\mathrm{MH}^{+}\right)$; HRMS (FAB) calcd for $\mathrm{C}_{29} \mathrm{H}_{42} \mathrm{~N}_{3} \mathrm{O}_{7} \mathrm{~S}\left(\mathrm{MH}^{+}\right)$576.2743, found 576.2761; $[\alpha]_{\mathrm{D}}{ }^{31}=+13.5\left(c 1.00, \mathrm{CHCl}_{3}\right)$; IR $\left(\mathrm{cm}^{-1}, \mathrm{CHCl}_{3}\right) 3417,1715,1336,1231,1151$, $1092,765,744,668$.

\section{Cells and viruses}

MT-2 cells were grown in an RPMI 1640-based culture medium supplemented with 15\% fetal calf serum (FCS, HyClone Laboratories, Logan, Utah, USA) plus $50 \mathrm{U}$ of penicillin and $50 \mu \mathrm{g}$ of streptomycin per mL. The following HIV-1 strains were used for the drug susceptibility assay: HIV-1 $1_{\text {LAI }}$, a clinical HIV-1 strain isolated from a drug-naive patient with AIDS, HIV-1 $1_{\text {ERSI04pre, and }}$ three HIV-1 clinical isolates that were originally isolated from heavily pretreated patients, $\mathrm{HIV}-\mathrm{l}_{\mathrm{TM}}$, HIV-1 ${ }_{\mathrm{MM}}$ and HIV-1 ${ }_{\mathrm{JSL}}$, which were genotypically and phenotypically characterized as multi-drugresistant HIV-1 variants. Amino acid substitutions identified in the protease-encoding region are as follows:

HIV-1 ${ }_{\text {I04pre }}$ L63P

HIV-1 $_{\text {TM }} \quad$ L10I/K14R/R41K/M46I/I54V/L63P/A71V/V82A/L90M/I93L 
HIV-1 $_{\text {MM }} \quad$ L10I/K43T/M46I/I54V/L63P/A71V/V82A/L90M/Q92K

HIV-1 $_{\text {JSL }} \quad$ L10I/L24I/L33F/E35D/M36I/N37S/M46I/I54V/R57K/I62V/L63P/A71V/G73S/V82A

\section{Anti-HIV assay}

The sensitivity of HIV-1 $1_{\text {LAI }}$ against various agents was determined as previously described (ref. Koh, Y. et al., Antimicrob. Agents Chemother. 2003, 47: 3123-3129). Briefly, MT-2 cells (2 x $10^{3} /$ well) were exposed to $10050 \%$ tissue culture infective doses $\left(\mathrm{TCID}_{50}\right)$ of $\mathrm{HIV}-1_{\mathrm{LAI}}$ in the presence of various concentrations of a test compound in 96-well microculture plates and incubated at $37^{\circ} \mathrm{C}$ for 7 days (final volume: $200 \mu \mathrm{L} /$ well). After $100 \mu \mathrm{L}$ of the medium was removed from each well, $10 \mu \mathrm{L}$ of 3-(4,5-dimethylthiazol-2-yl)-2,5-diphenyltetrazolium bromide (MTT) solution $(7.5 \mathrm{mg} / \mathrm{mL})$ in PBS was added to each well in the plate, followed by incubation at $37^{\circ} \mathrm{C}$ for $2 \mathrm{~h}$. After incubation, to dissolve the formazan crystals, $100 \mu \mathrm{L}$ of acidified isopropanol containing $4 \%$ (v/v) Triton X-100 was added to each well, the optical density (OD570) was measured in a microplate reader $\left(\mathrm{V}_{\max }\right.$; Molecular Devices, Sunnyvale, Calif.). All assays were performed in at least triplicate.

Phytohemagglutinin (PHA)-treated peripheral blood mononuclear cells (PBMC) (1 x 105 well) were exposed to $50 \mathrm{TCID}_{50}$ of each HIV-1 clinical isolate in the presence or absence of various concentrations of a test compound in 96-well microculture plates (final volume: 200 $\mu \mathrm{L} /$ well). The amounts of p24 antigen produced by the cells were determined on day 7 in culture using a fully automated chemiluminescent enzyme immunoassay system (Lumipulse F; Fujirebio Inc, Tokyo, Japan) (Cite Koh et al., Ref. 35). Drug concentrations that resulted in 50\% inhibition $\left(\mathrm{IC}_{50}\right)$ of p24 antigen production were determined by comparison with the p24 production level in drug-free control cell cultures. All assays were performed in triplicate or greater replicates. 


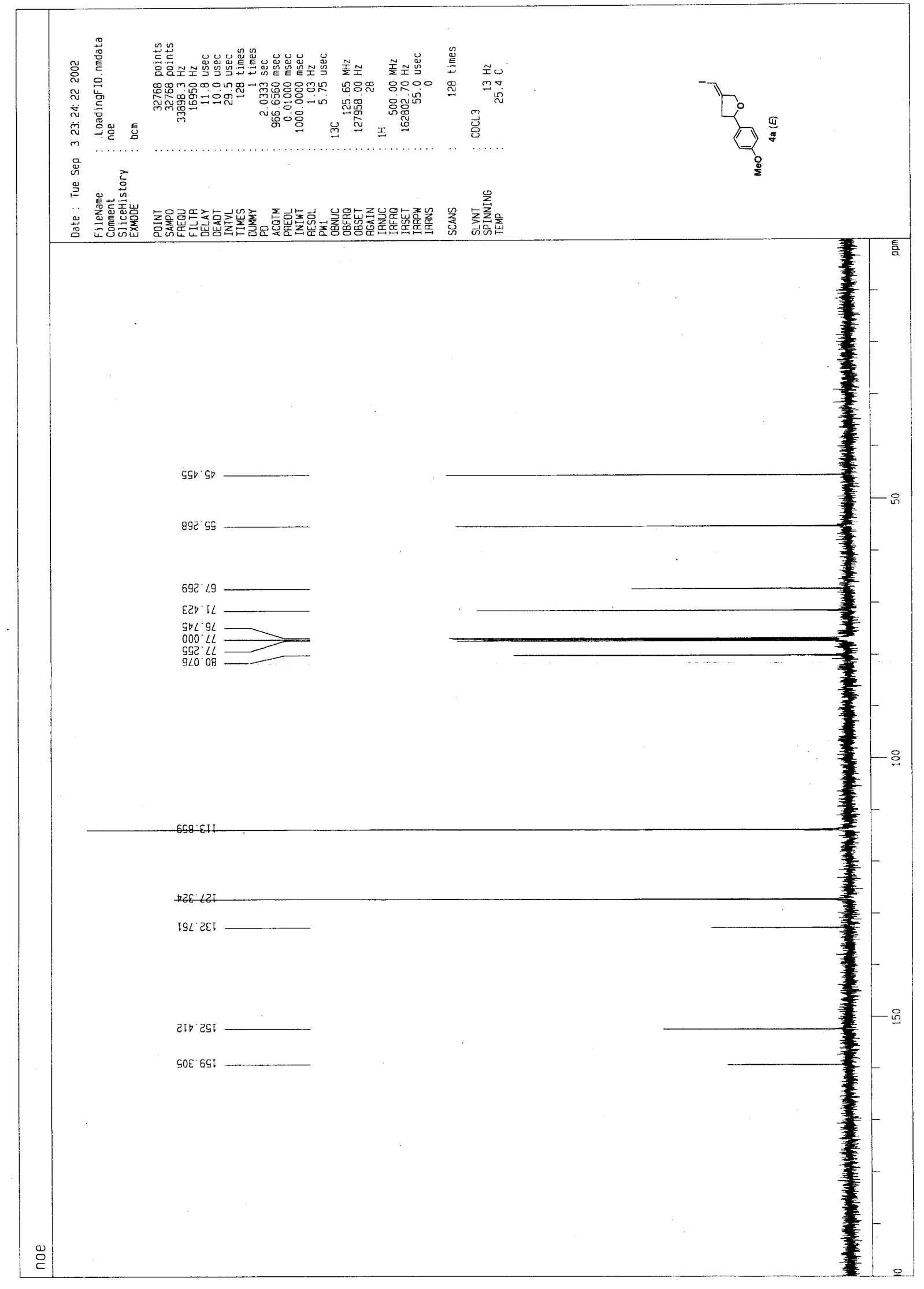




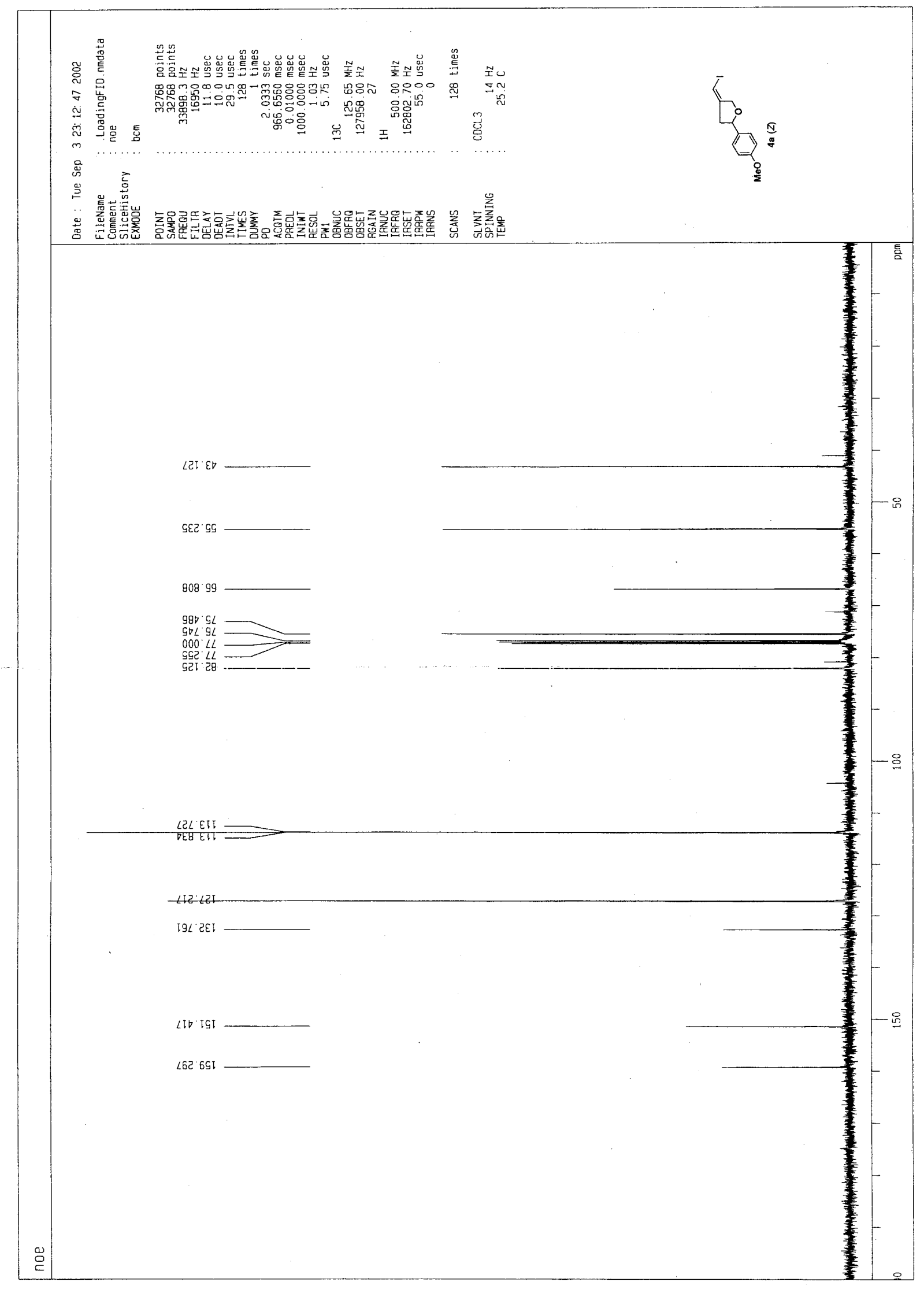




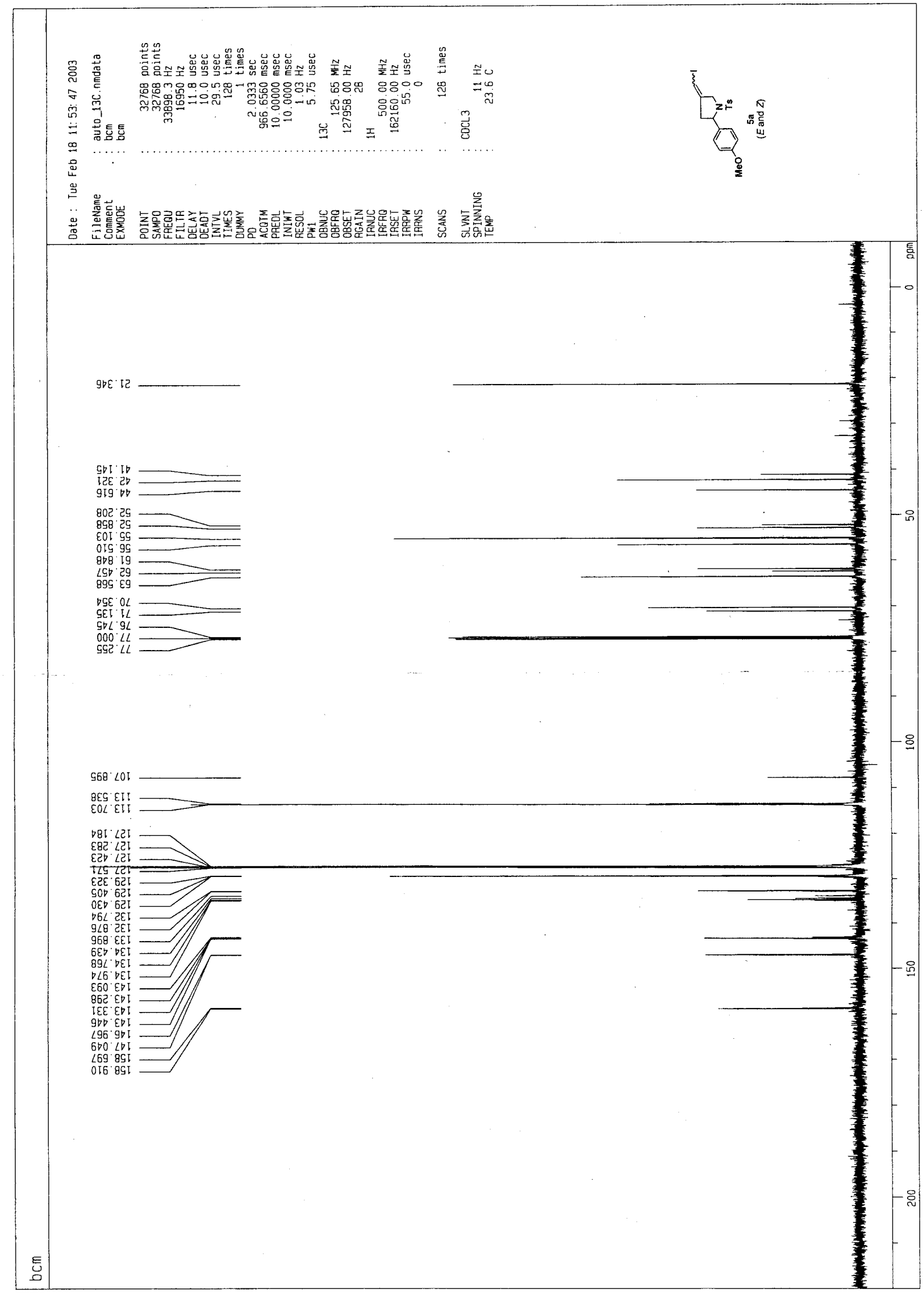




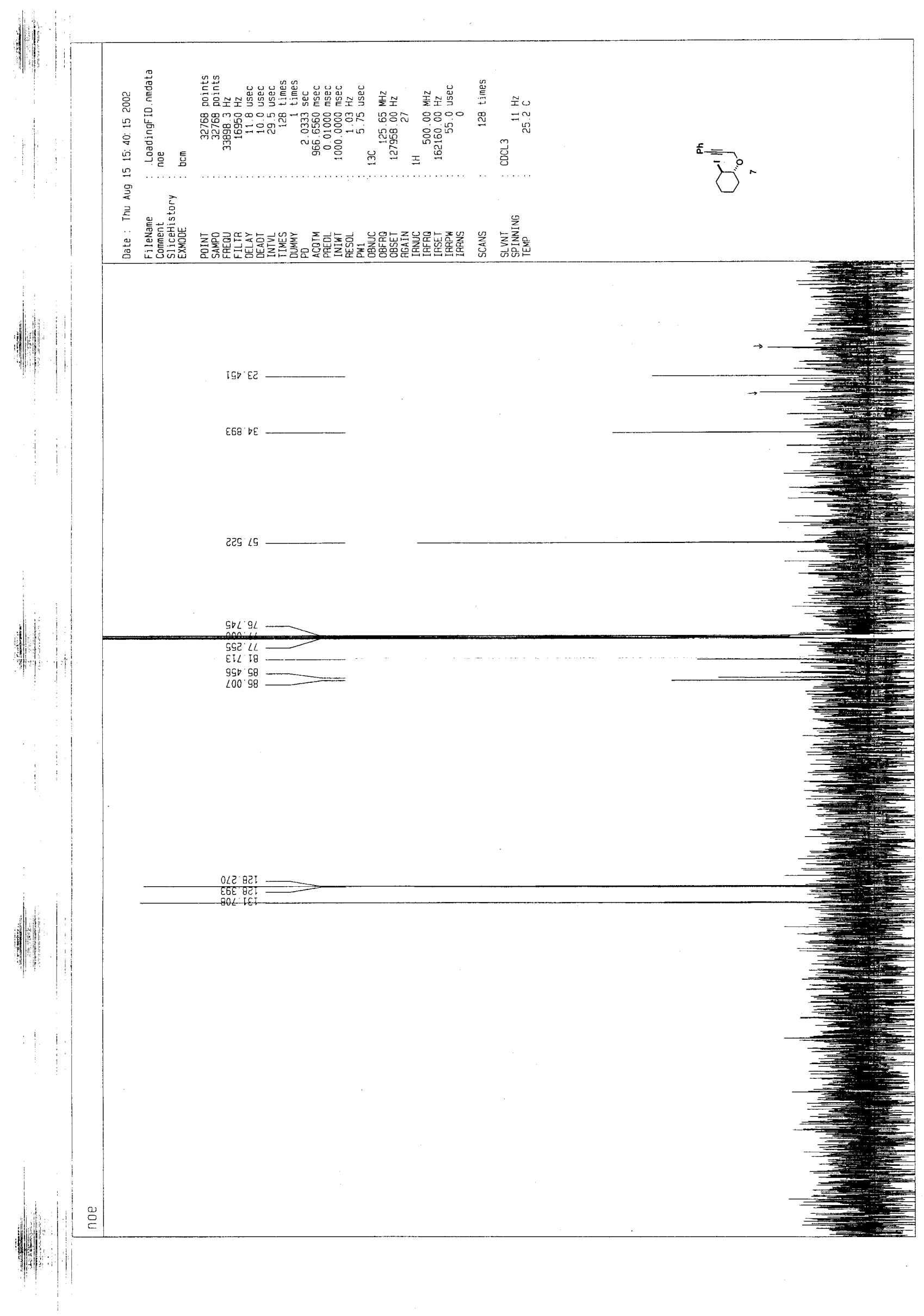




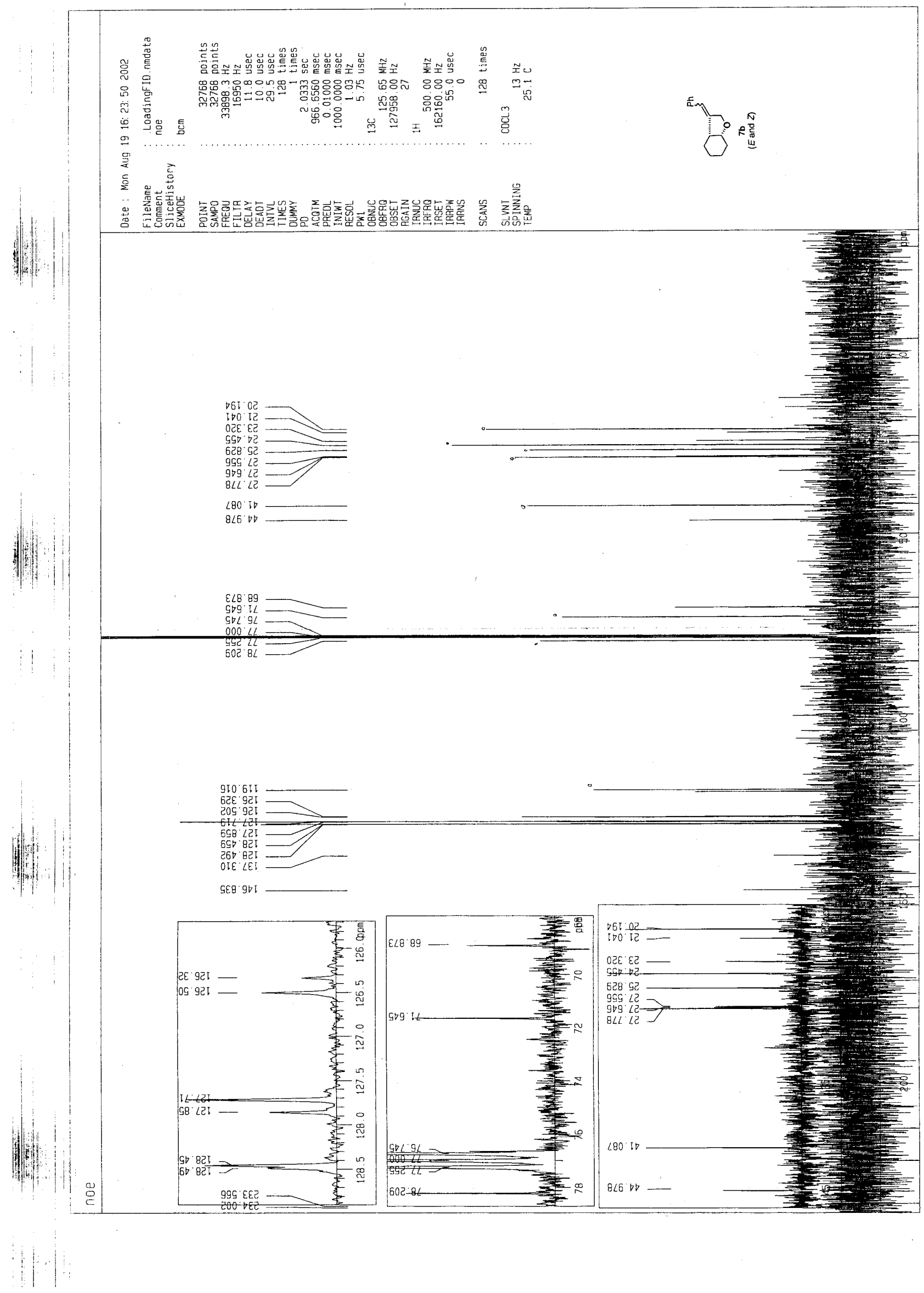




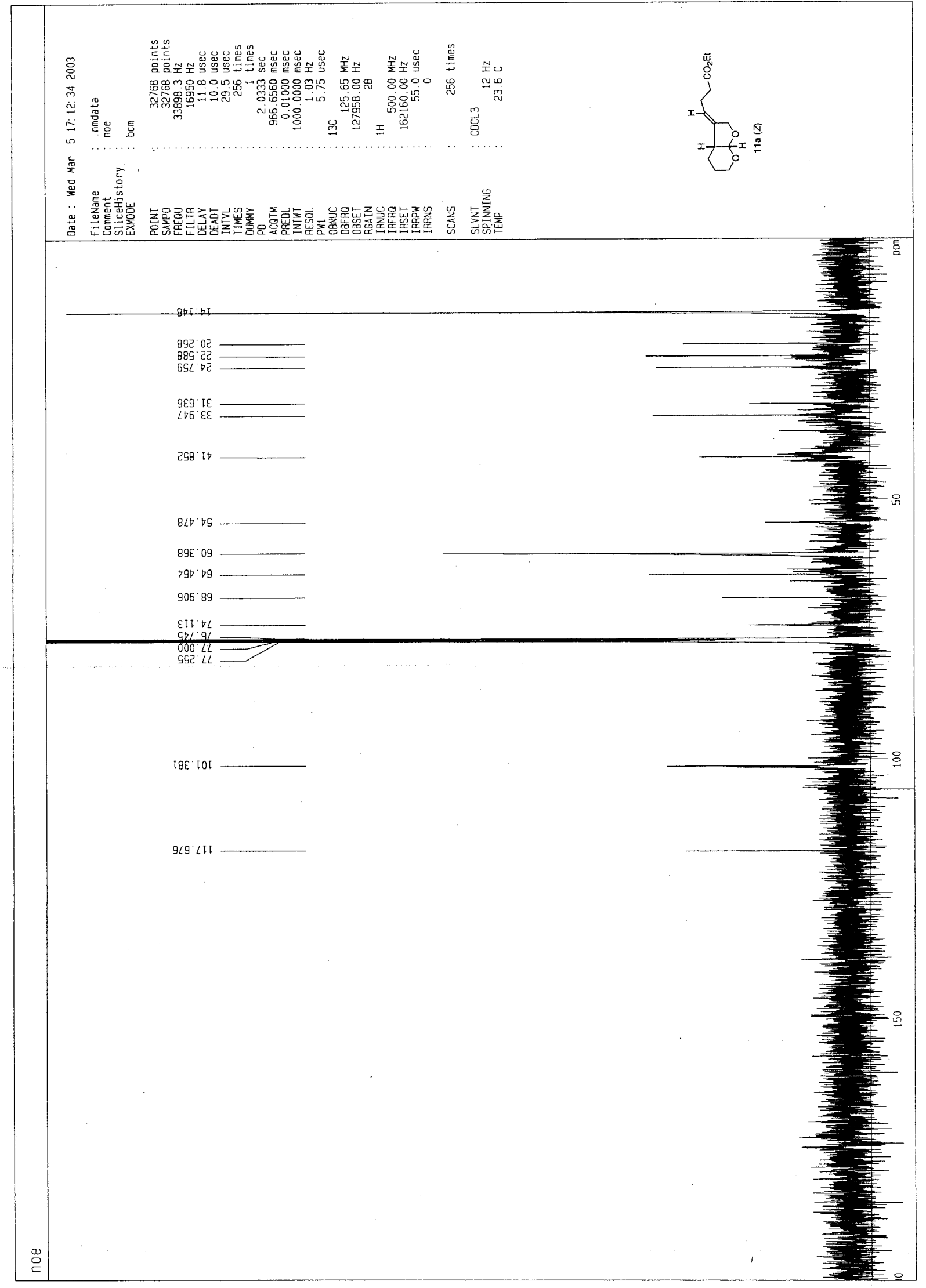




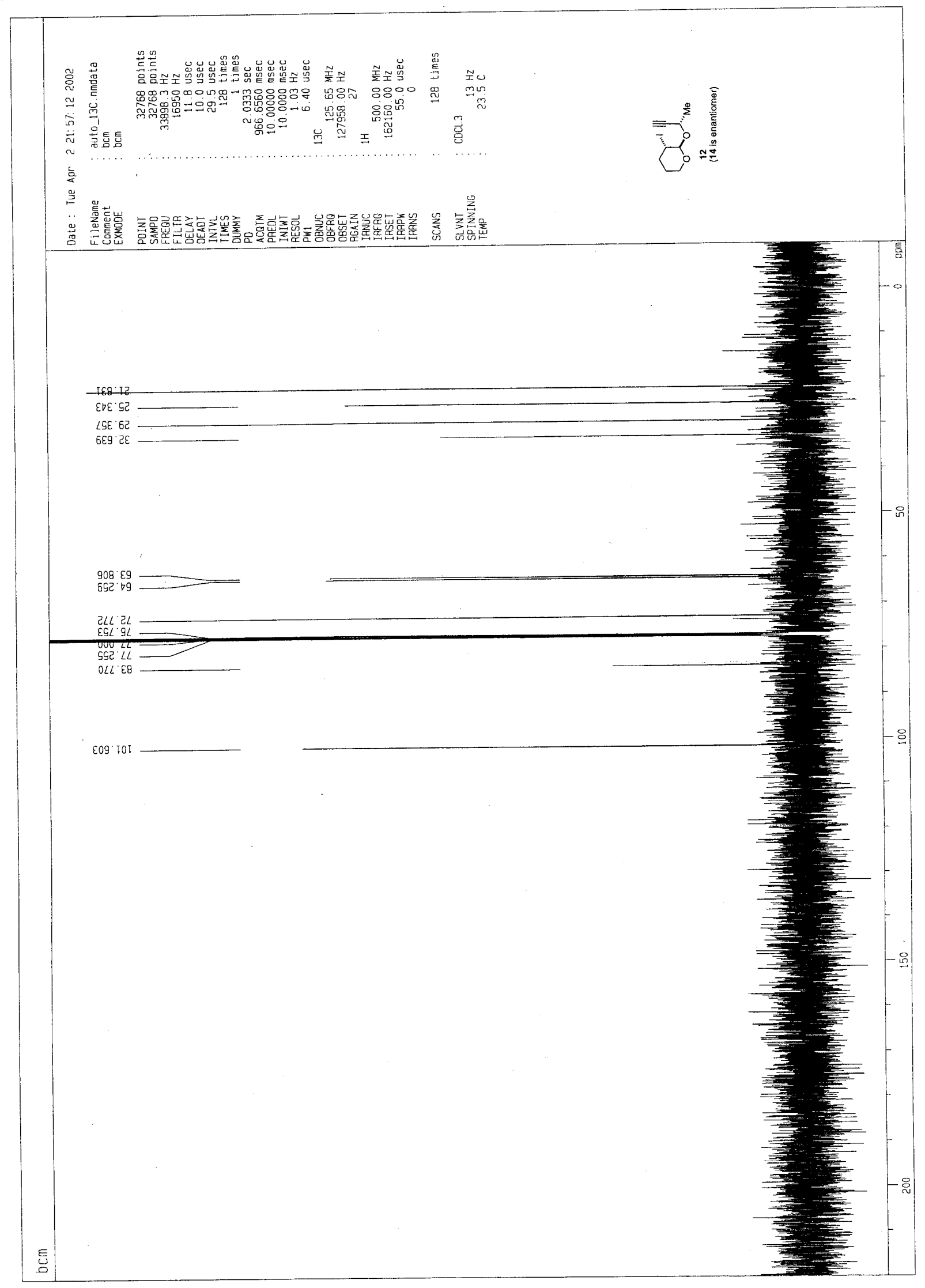




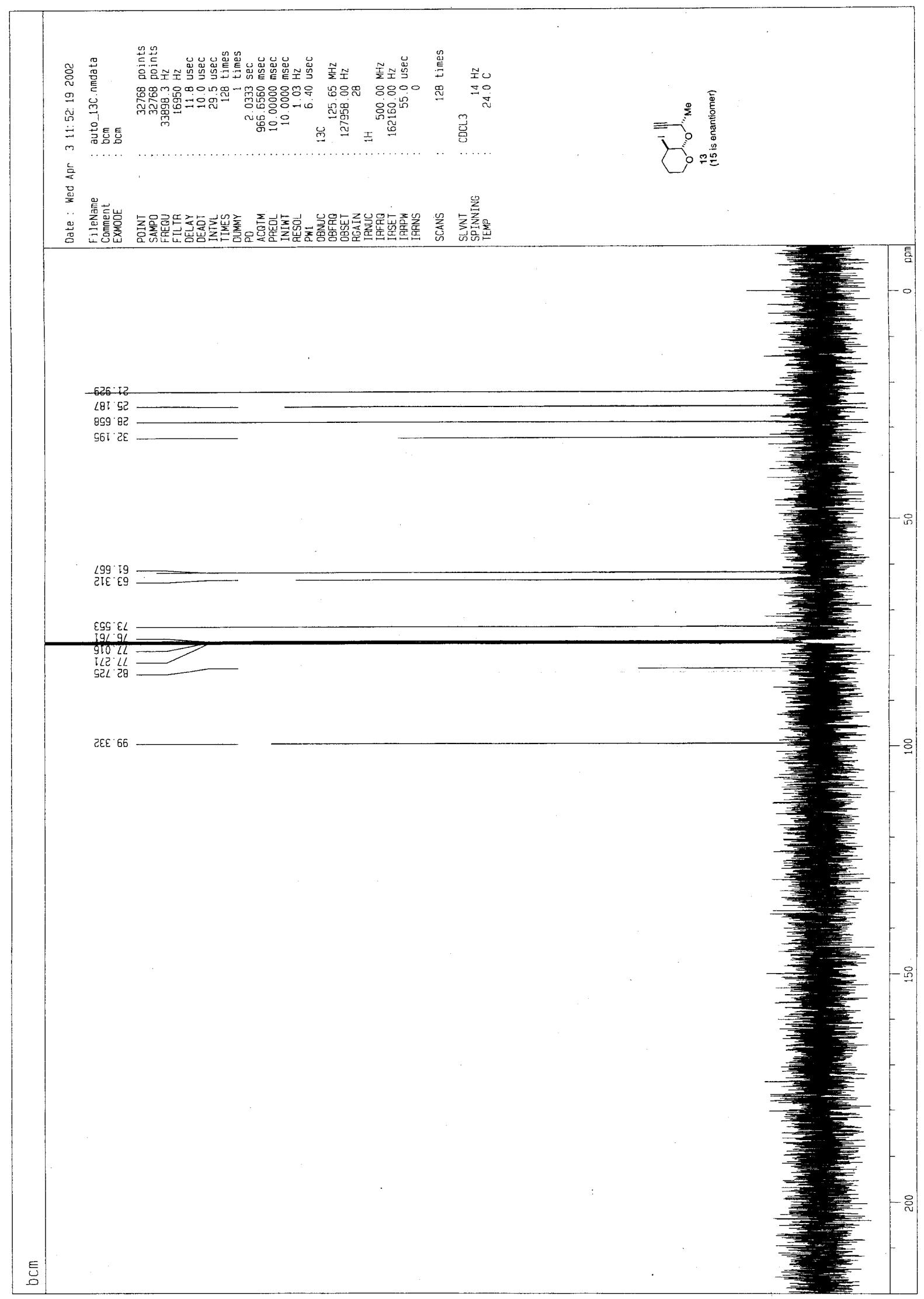




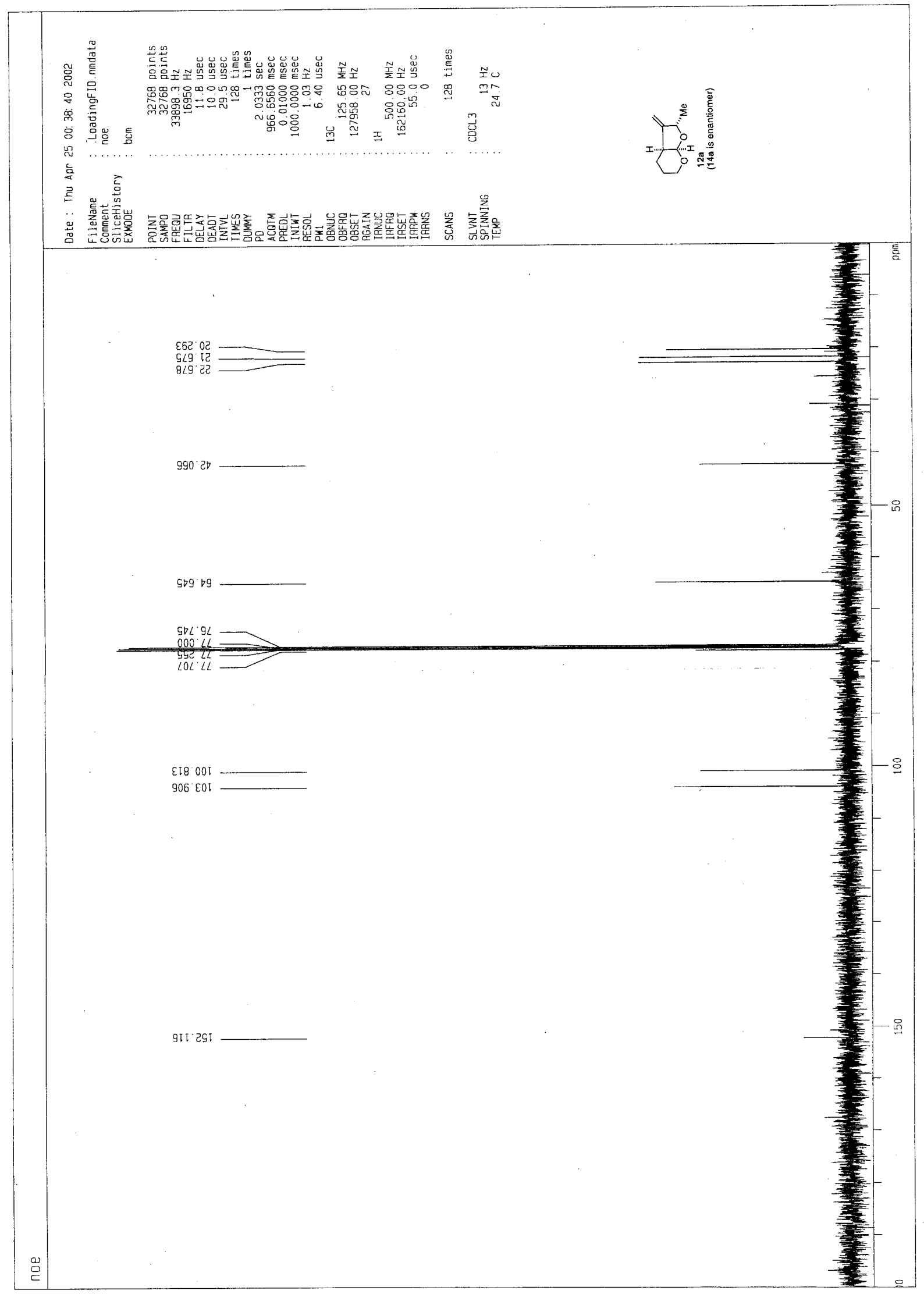




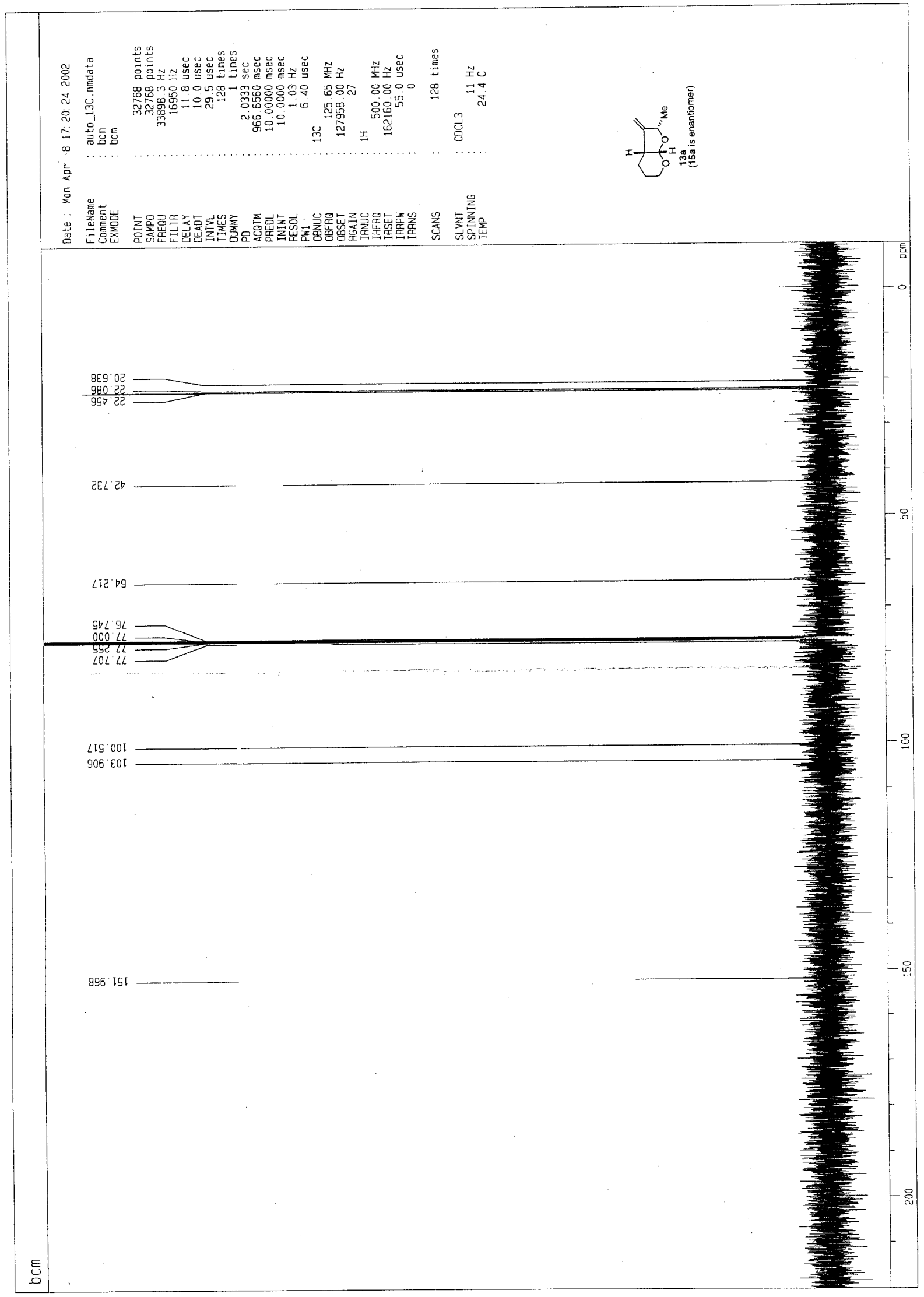




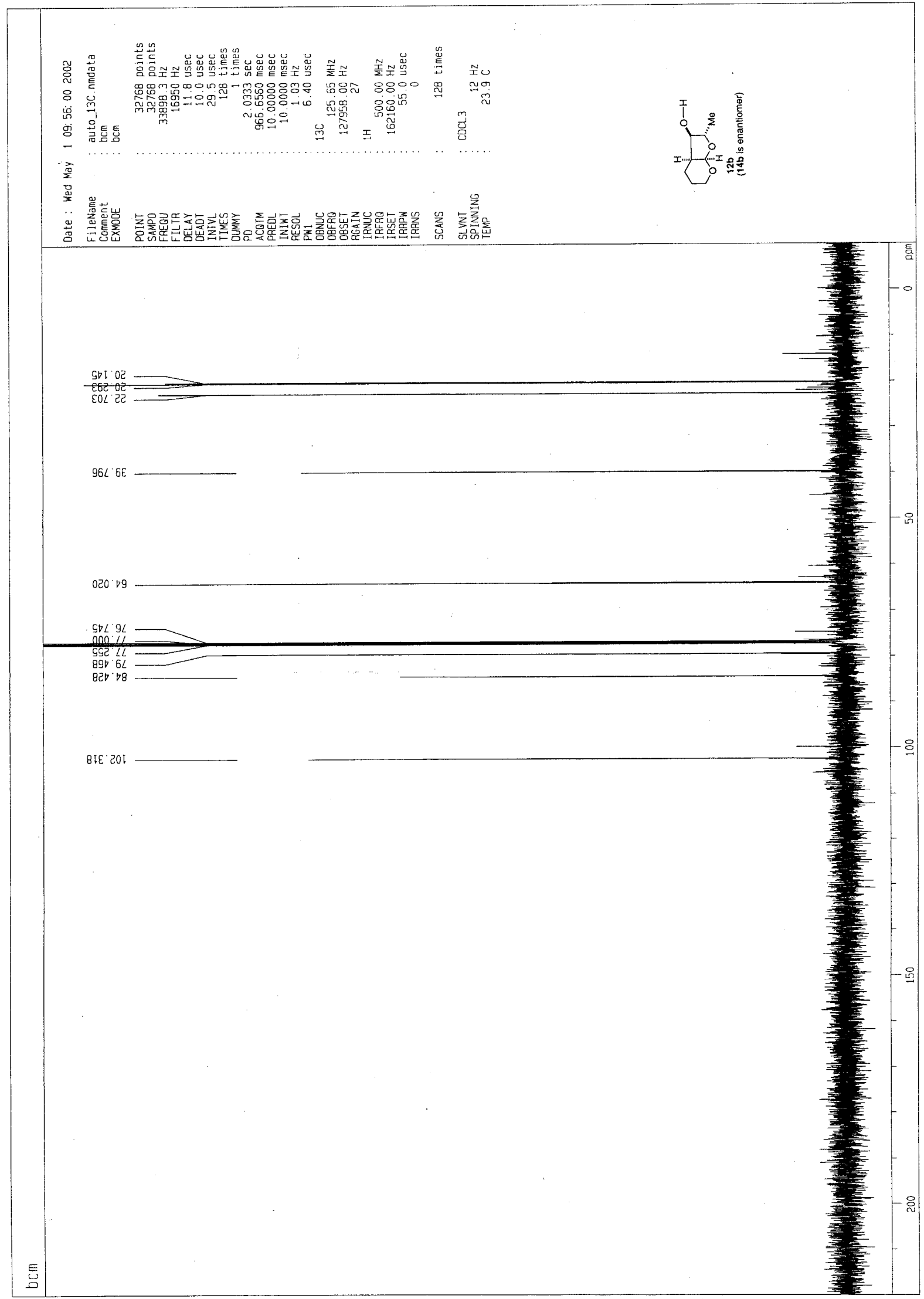




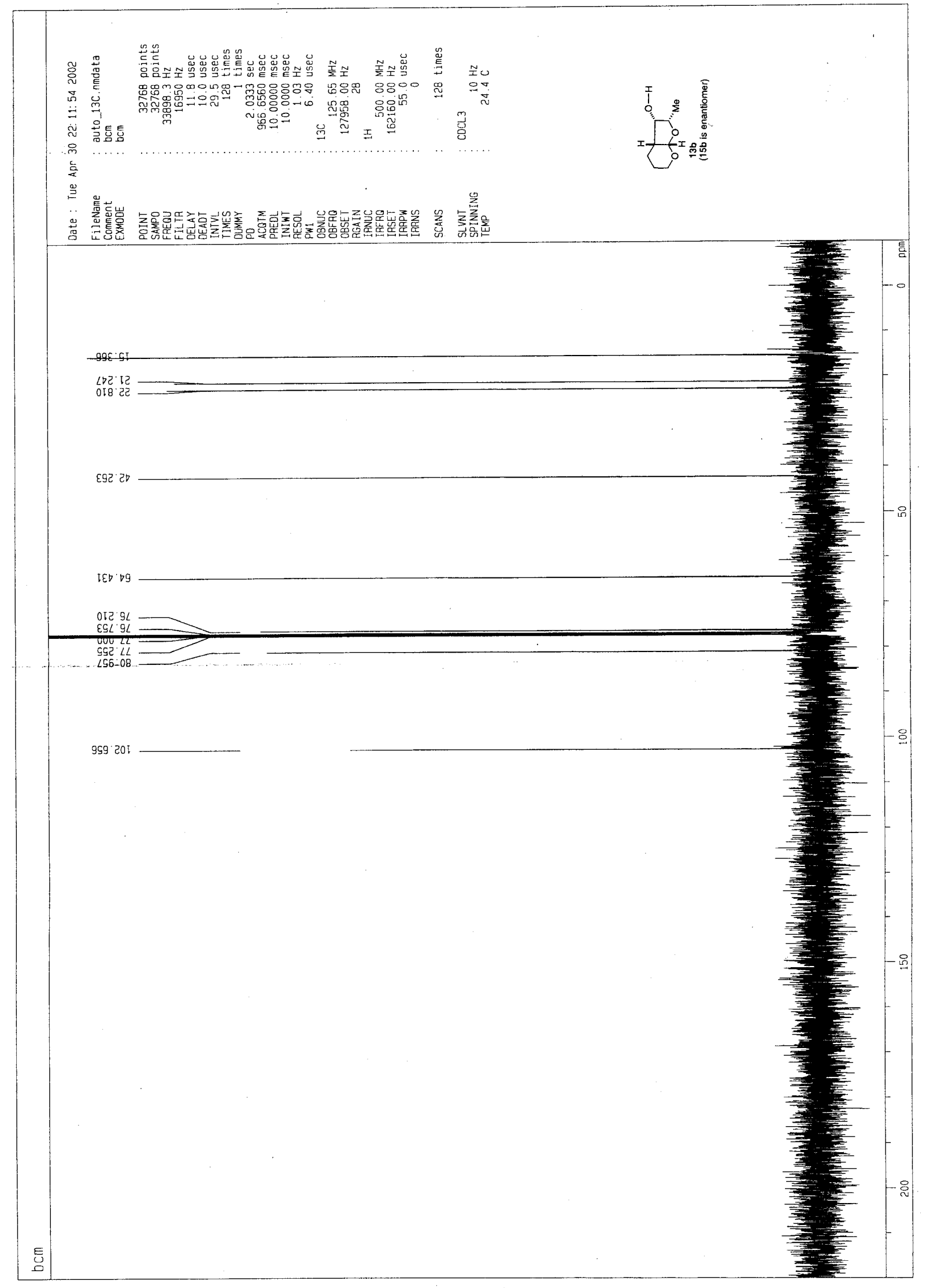

S28 


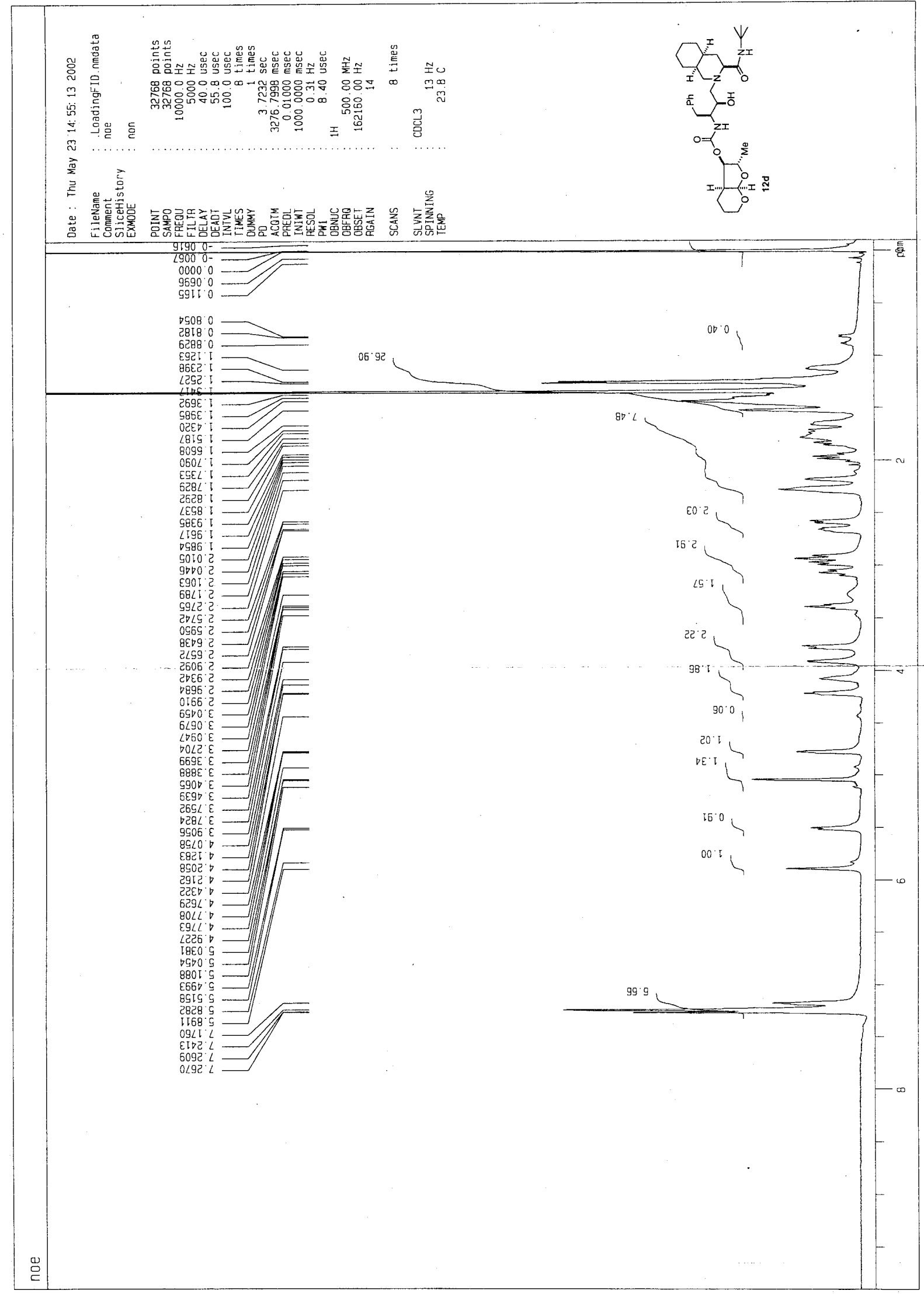




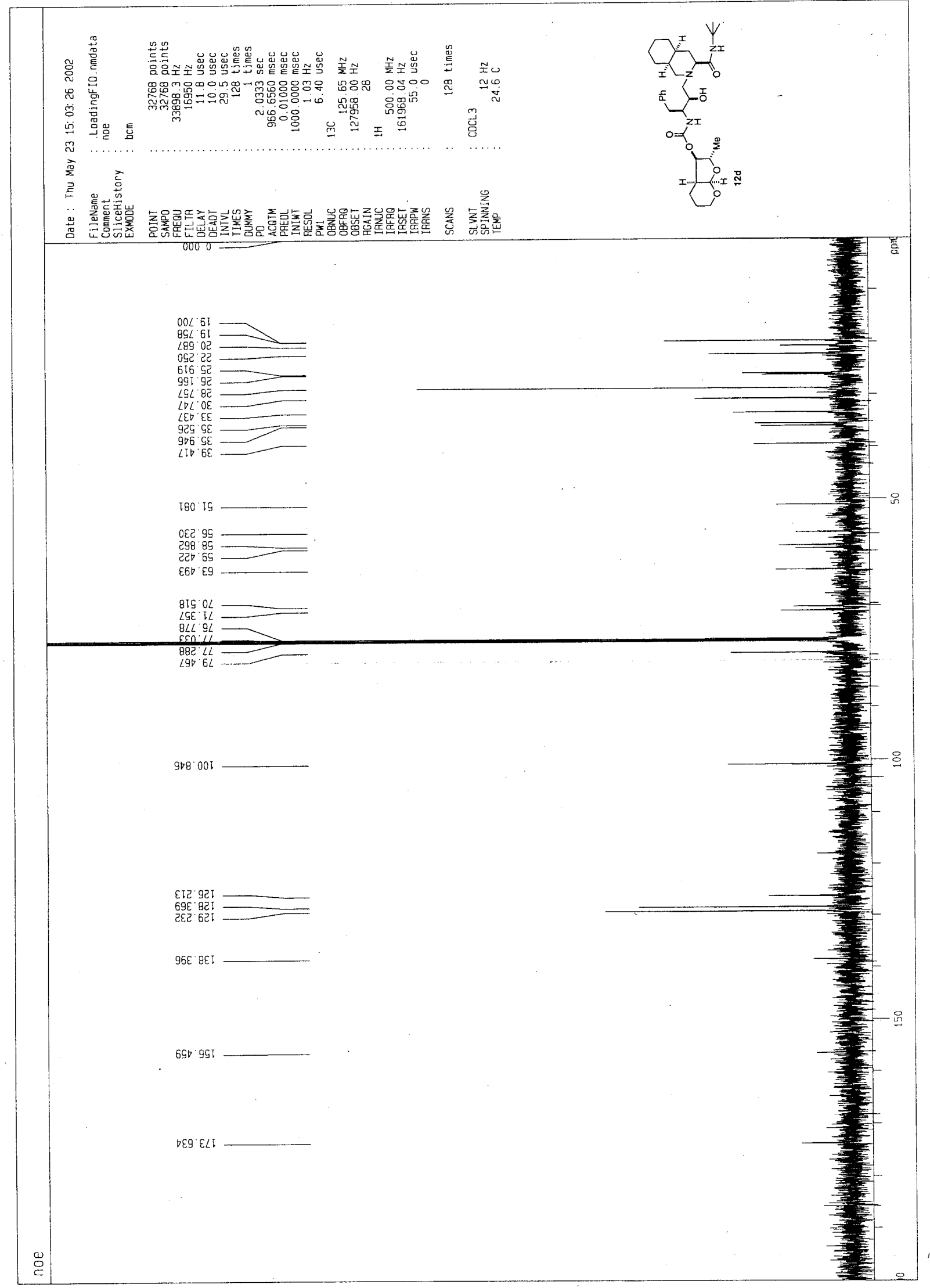




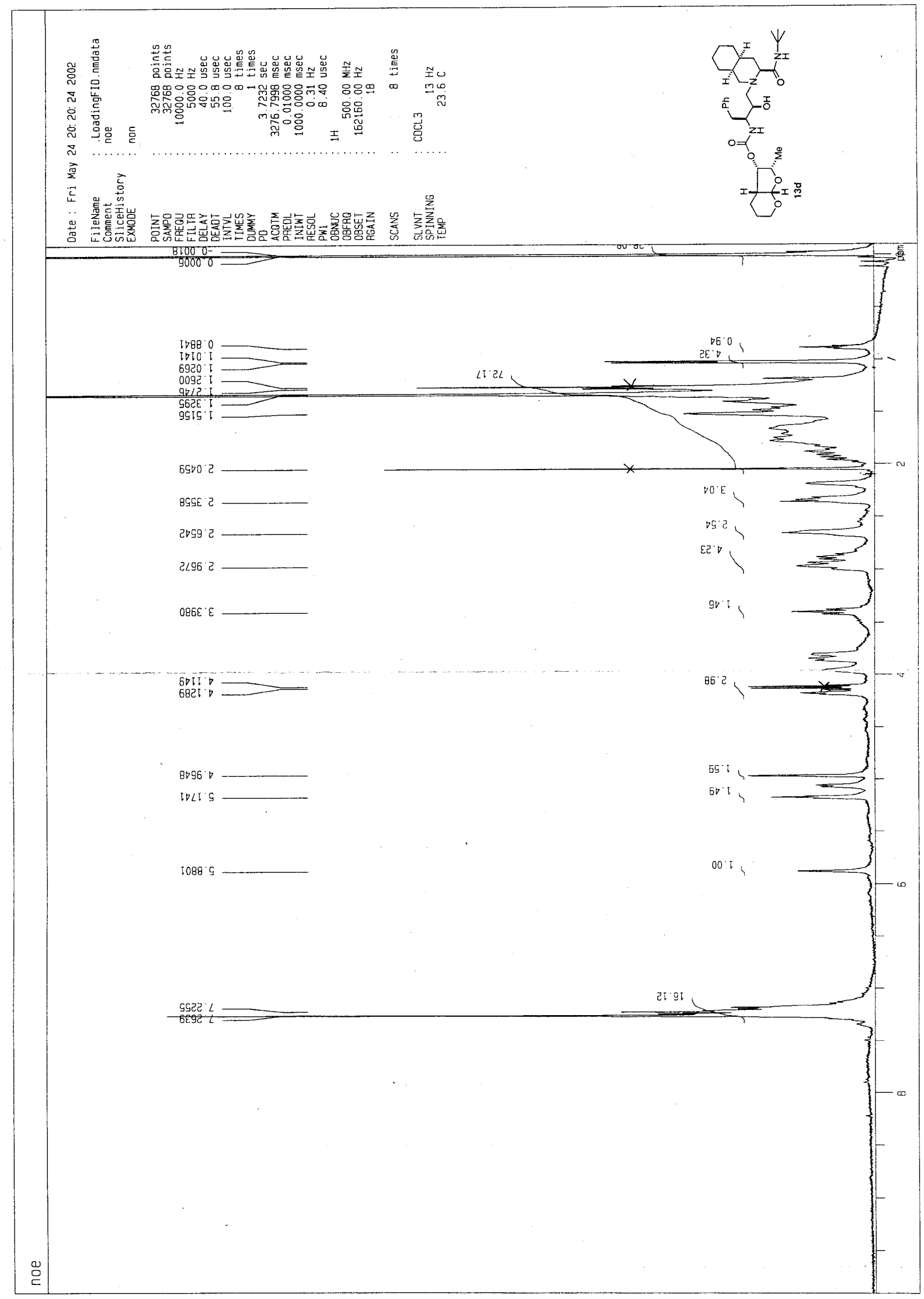




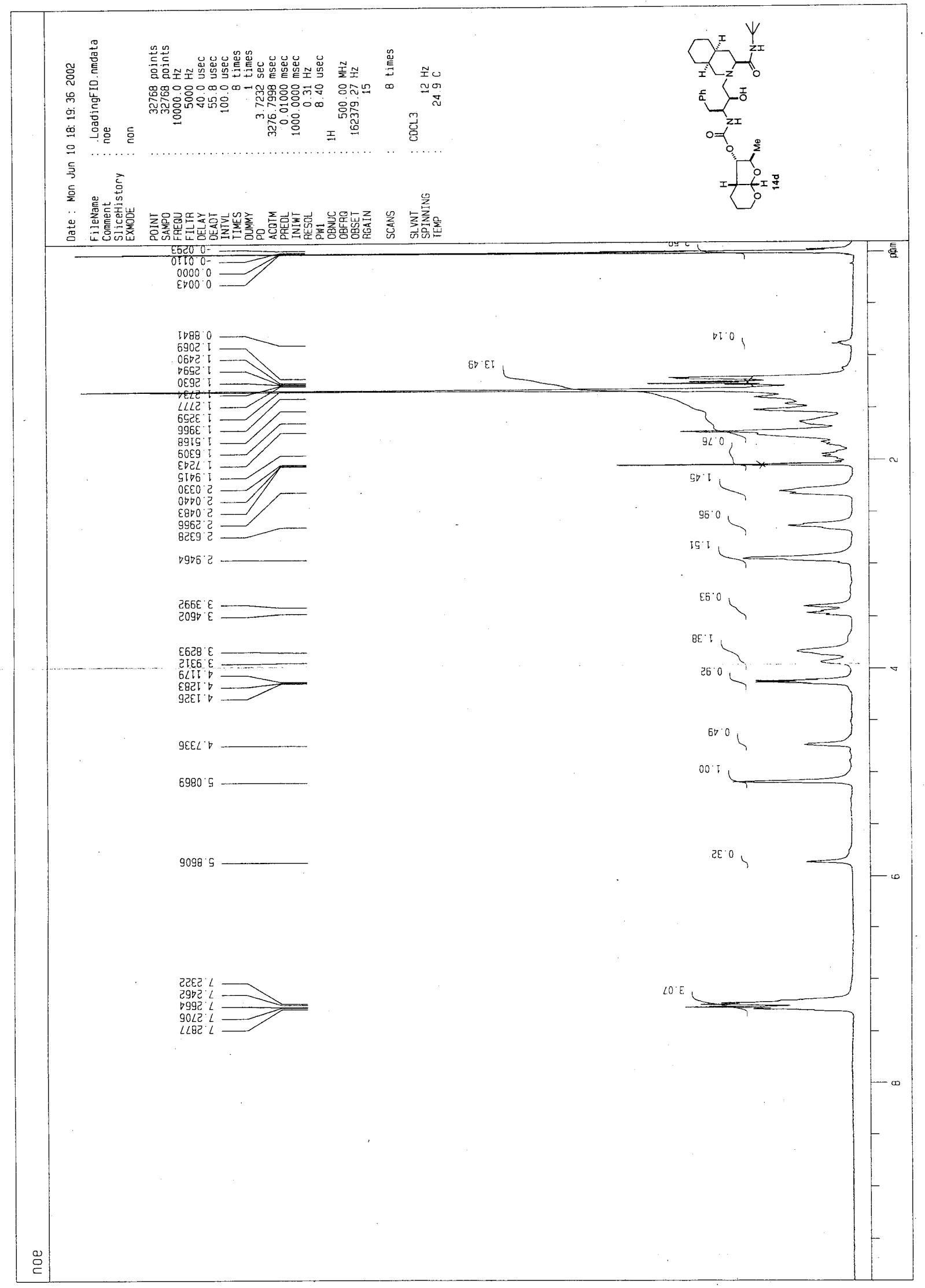




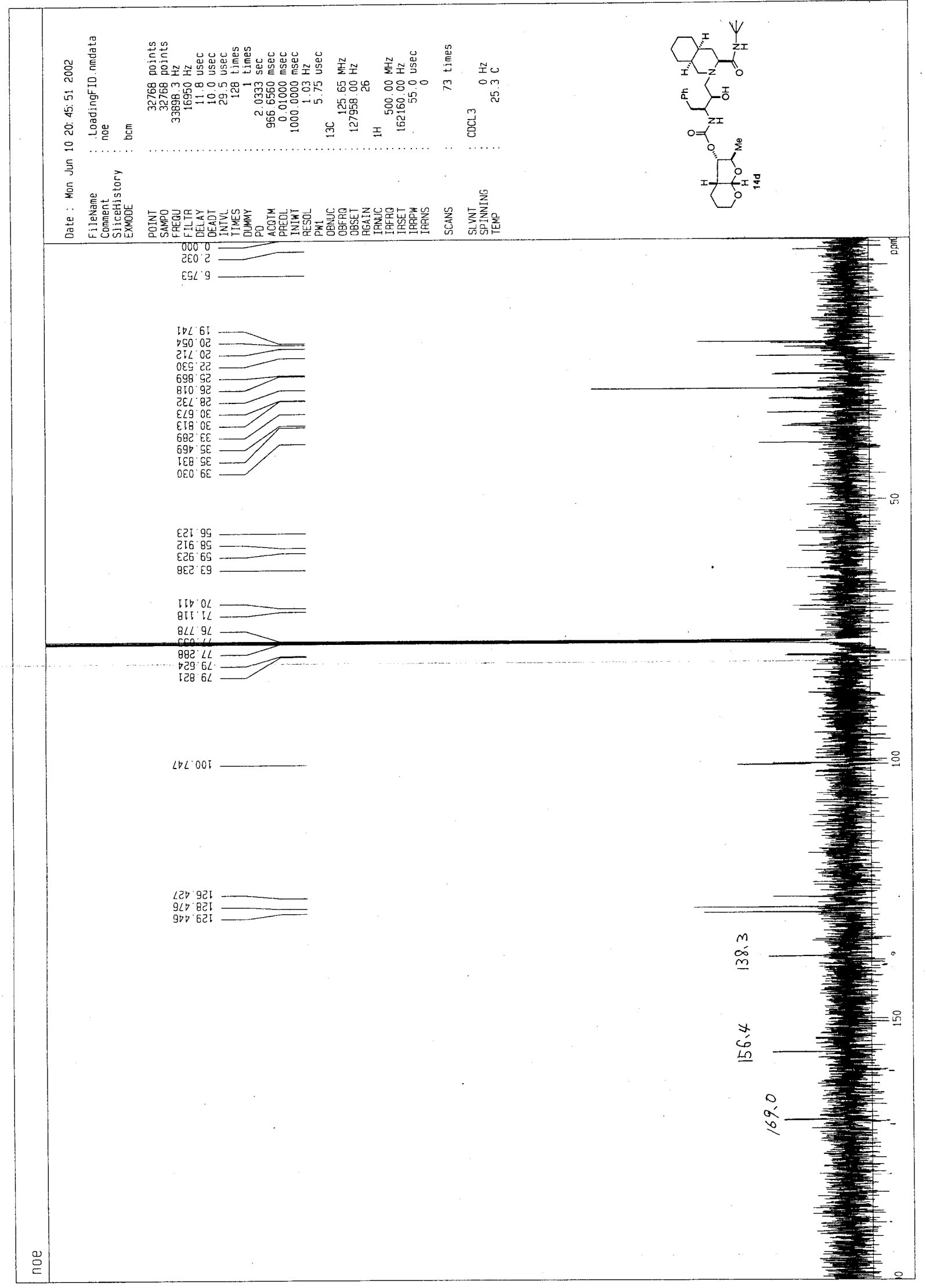




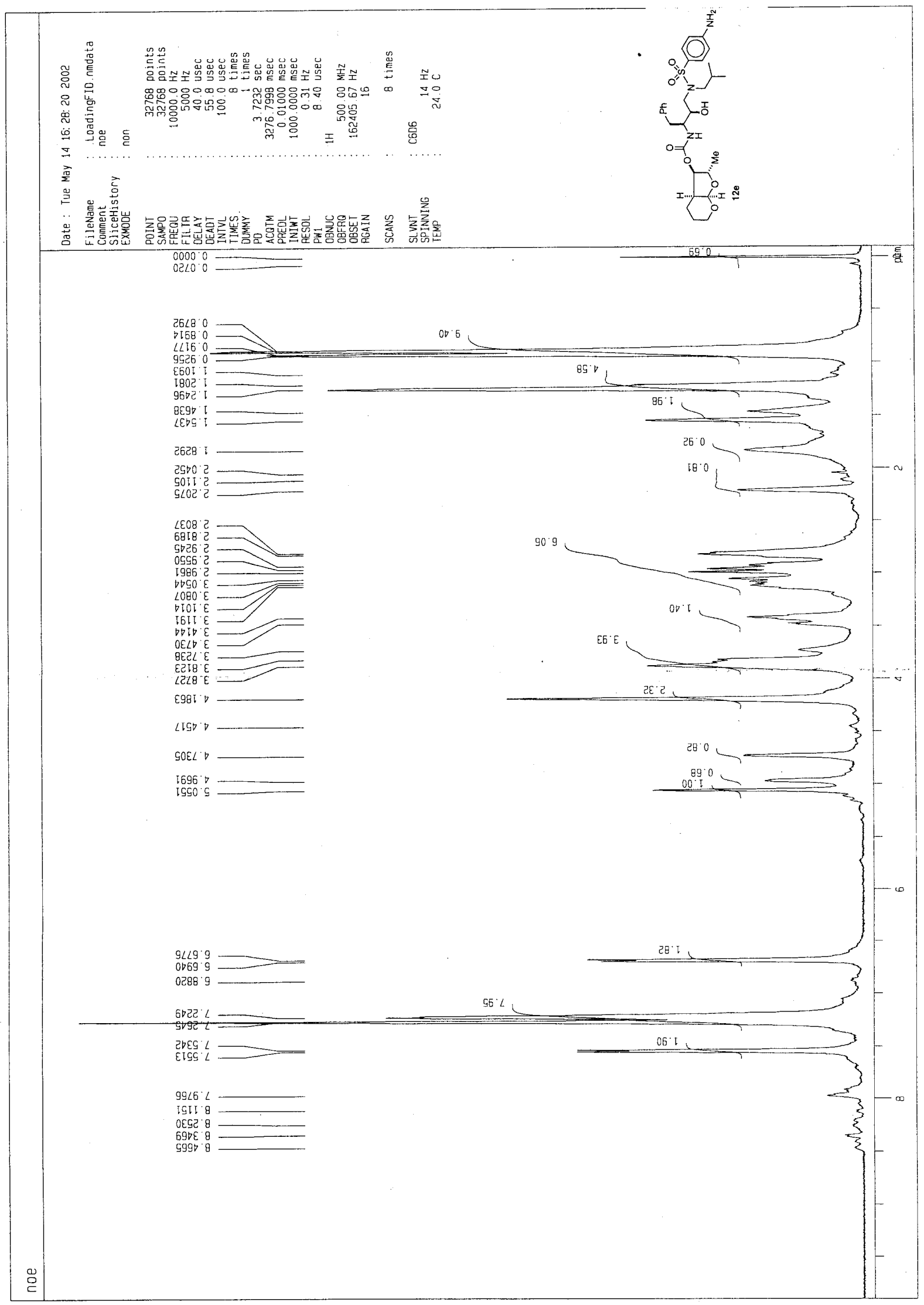




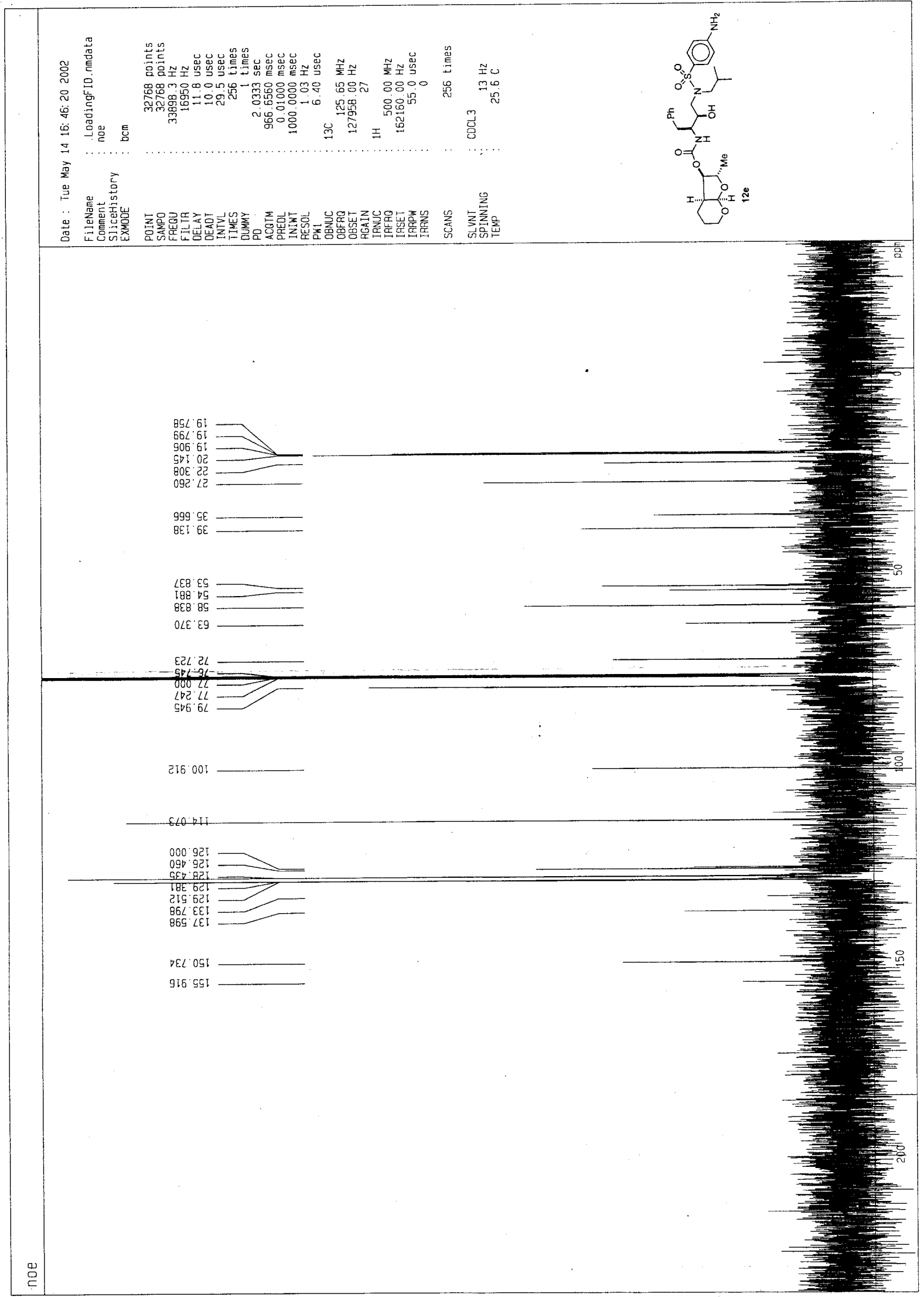




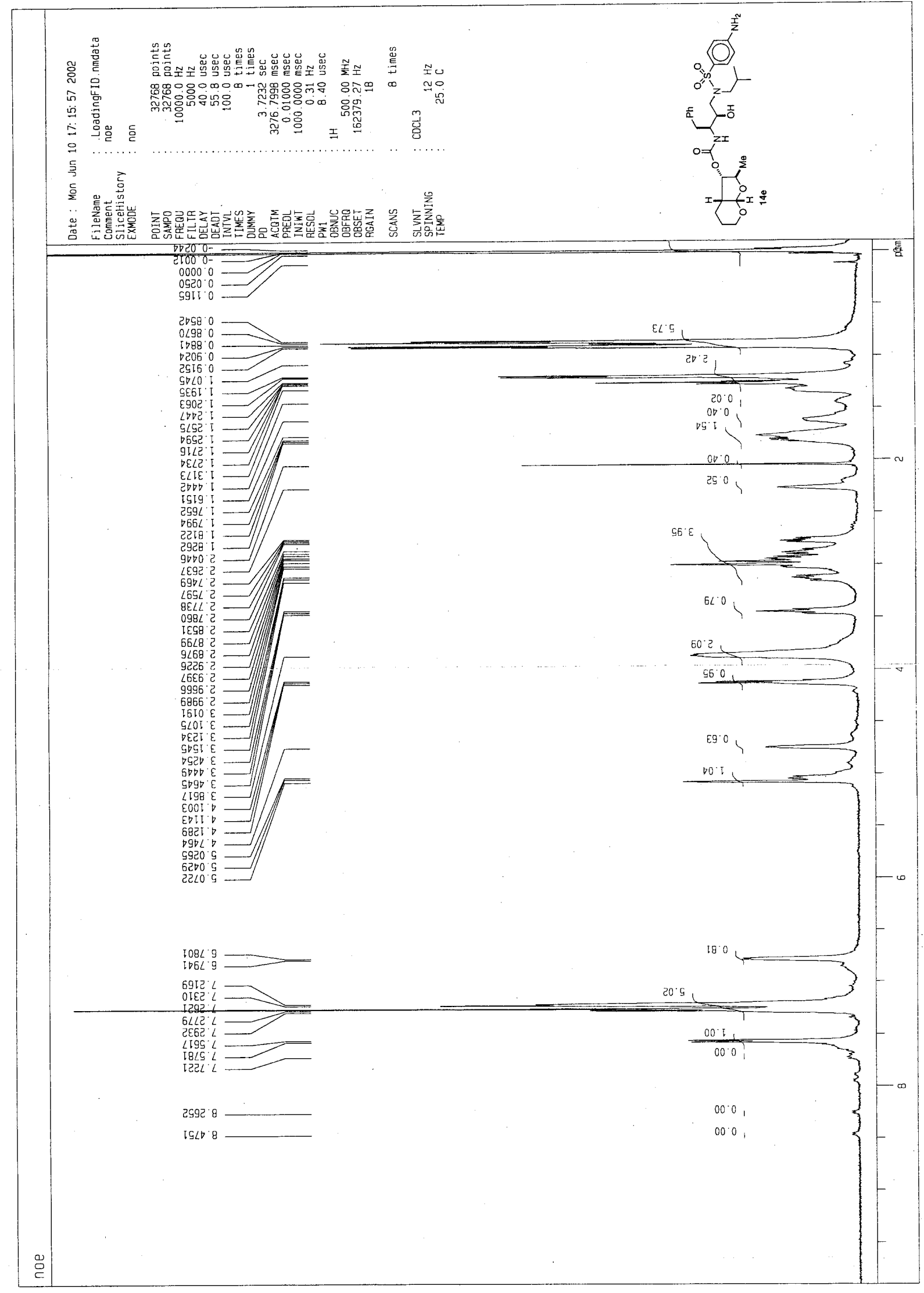




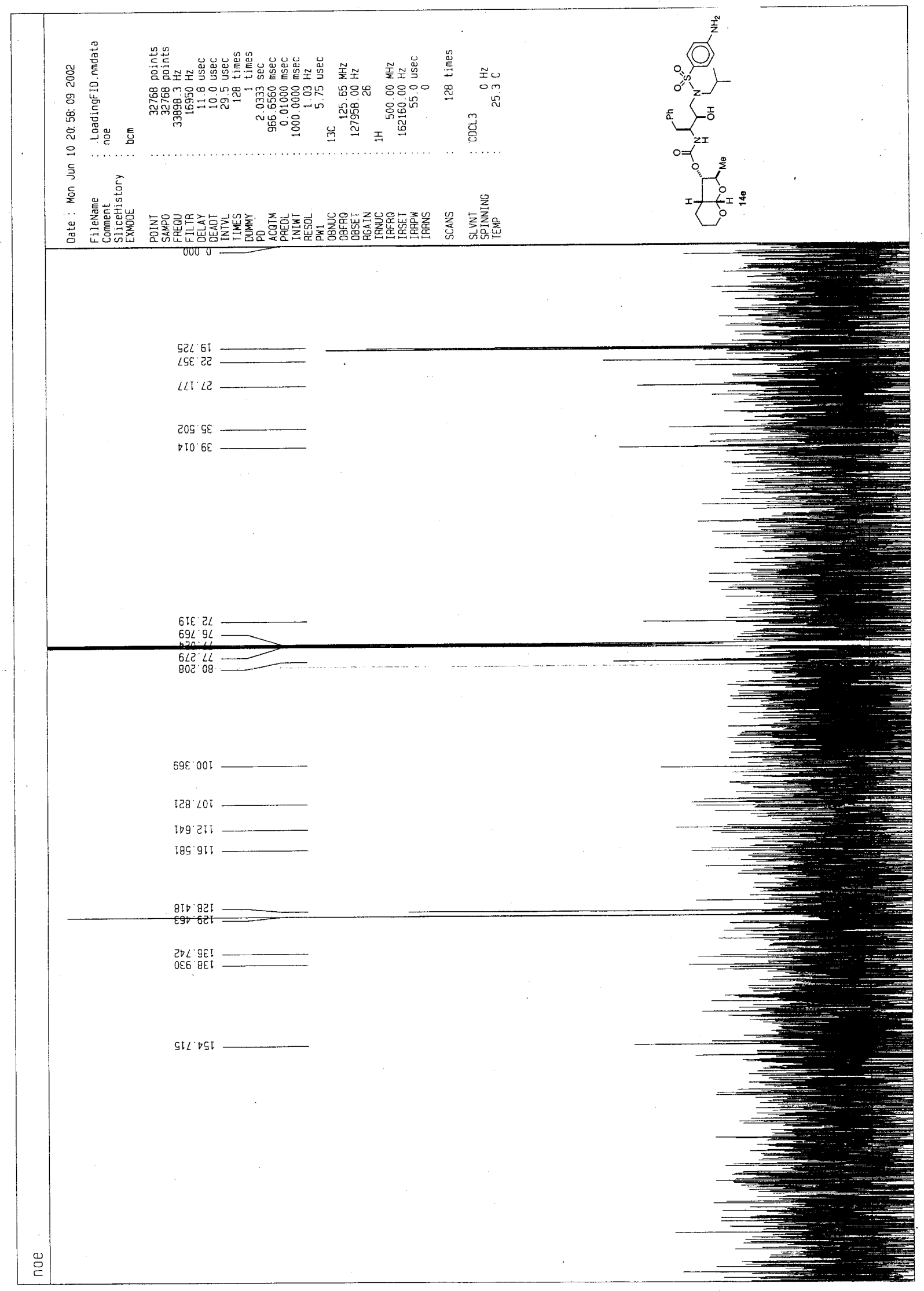

